\title{
Surface and boundary layer exchanges of volatile organic compounds, nitrogen oxides and ozone during the GABRIEL campaign
}

\author{
L. Ganzeveld ${ }^{1,2}$, G. Eerdekens ${ }^{2,4}$, G. Feig ${ }^{3}$, H. Fischer ${ }^{2}$, H. Harder ${ }^{2}$, R. Königstedt ${ }^{2}$, D. Kubistin ${ }^{2}$, M. Martinez ${ }^{2}$, \\ F. X. Meixner ${ }^{3}$, H. A. Scheeren ${ }^{5}$, V. Sinha ${ }^{2}$, D. Taraborrelli ${ }^{2}$, J. Williams ${ }^{2}$, J. Vilà-Guerau de Arellano ${ }^{1}$, and \\ J. Lelieveld ${ }^{2}$ \\ ${ }^{1}$ Department of Environmental Sciences, Wageningen University and Research Centre, Droevendaalsesteeg 4, \\ 6708 PB, Wageningen, The Netherlands \\ ${ }^{2}$ Department of Atmospheric Chemistry, Max-Plank Institute for Chemistry, Mainz, Germany \\ ${ }^{3}$ Department of Biogeochemistry, Max-Plank Institute for Chemistry, Mainz, Germany \\ ${ }^{4}$ Research Group Plant and Vegetation Ecology, Department of Biology, University of Antwerp, Antwerp, Belgium \\ ${ }^{5}$ European Commission Joint Research Centre, Institute for Environment and Sustainability, \\ Climate Change Unit, Ispra, Italy
}

Received: 6 May 2008 - Published in Atmos. Chem. Phys. Discuss.: 16 June 2008

Revised: 28 August 2008 - Accepted: 5 September 2008 - Published: 27 October 2008

\begin{abstract}
We present an evaluation of sources, sinks and turbulent transport of nitrogen oxides, ozone and volatile organic compounds (VOC) in the boundary layer over French Guyana and Suriname during the October 2005 GABRIEL campaign by simulating observations with a single-column chemistry and climate model (SCM) along a zonal transect. Simulated concentrations of $\mathrm{O}_{3}$ and $\mathrm{NO}$ as well as $\mathrm{NO}_{2}$ photolysis rates over the forest agree well with observations when a small soil-biogenic NO emission flux was applied. This suggests that the photochemical conditions observed during GABRIEL reflect a pristine tropical low- $\mathrm{NO}_{\mathrm{x}}$ regime. The SCM uses a compensation point approach to simulate nocturnal deposition and daytime emissions of acetone and methanol and produces daytime boundary layer mixing ratios in reasonable agreement with observations. The area average isoprene emission flux, inferred from the observed isoprene mixing ratios and boundary layer height, is about half the flux simulated with commonly applied emission algorithms. The SCM nevertheless simulates too high isoprene mixing ratios, whereas hydroxyl concentrations are strongly underestimated compared to observations, which can at least partly explain the discrepancy. Furthermore, the model substantially overestimates the isoprene oxidation products methlyl vinyl ketone (MVK) and methacrolein (MACR) partly
\end{abstract}

Correspondence to: L. Ganzeveld laurens.ganzeveld@wur.nl due to a simulated nocturnal increase due to isoprene oxidation. This increase is most prominent in the residual layer whereas in the nocturnal inversion layer we simulate a decrease in MVK and MACR mixing ratios, assuming efficient removal of MVK and MACR. Entrainment of residual layer air masses, which are enhanced in MVK and MACR and other isoprene oxidation products, into the growing boundary layer poses an additional sink for $\mathrm{OH}$ which is thus not available for isoprene oxidation. Based on these findings, we suggest pursuing measurements of the tropical residual layer chemistry with a focus on the nocturnal depletion of isoprene and its oxidation products.

\section{Introduction}

In October 2005 an intensive field campaign including ground-based and airborne measurements has been conducted over the Atlantic Ocean and French Guyana and Suriname to study the atmospheric oxidizing capacity and role of atmosphere-biosphere exchanges in this region (Lelieveld et al., 2008). To interpret these observations it is essential to assess the role of key precursors and controlling oxidation processes. This includes primary $\mathrm{OH}$ production, photolysis rates, water vapor and ozone, as well as the processes involved in the regeneration of $\mathrm{OH}$ and the influence of volatile organic compounds (VOCs), including methanol

Published by Copernicus Publications on behalf of the European Geosciences Union. 
$\left(\mathrm{CH}_{3} \mathrm{OH}\right)$ and acetone $\left(\mathrm{CH}_{3} \mathrm{COCH}_{3}\right)$. In addition, a main sink of $\mathrm{OH}$ over the tropical forest is associated with the large biogenic emissions of VOCs, mostly in the form of isoprene $\left(\mathrm{C}_{5} \mathrm{H}_{8}\right)$, and this must be properly quantified. The lack of $\mathrm{OH}$ and $\mathrm{HO}_{2}$ concentration measurements over tropical forests has until now posed a limitation in the interpretation of the various atmospheric chemistry measurements. For example, evaluation of the exchanges of VOCs over the tropical forest close to Manaus, Brazil, measured during the LBA-CLAIRE2001 (Kuhn et al., 2007) and TROFFEE campaigns (Karl et al., 2007), relied on indirect estimates of $\mathrm{OH}$ concentrations, whereas during GABRIEL the $\mathrm{OH}$ and $\mathrm{HO}_{2}$ radical concentrations were measured directly (Lelieveld et al., 2008).

In the LBA campaigns an important focus has been the measurement of atmosphere-biosphere exchanges of reactive trace gases and aerosols, deploying when possible flux measurement systems. Examples include the two LBAEUSTACH intensive field campaigns (Andreae et al., 2002) at a primary rainforest and a pasture site in the state of Rondonia in southwestern Brazil conducting eddy correlation, gradient and enclosure measurements to study the exchanges of VOCs, nitrogen oxides $\left(\mathrm{NO}_{\mathrm{x}}=\mathrm{NO}+\mathrm{NO}_{2}\right)$ and ozone. Such direct flux measurements are not available for the GABRIEL campaign; however, through the combined use of observations and models of surface and boundary layer exchanges, empirical estimates can be made and key processes studied. In this study we apply the Single Column chemistry and climate Model ECHAM4 (SCM) (Ganzeveld et al., 2002a, 2004 and 2006b). The representation of the tropical forest exchanges of reactive trace gases in this model has been extensively evaluated by comparison with observations (Ganzeveld et al., 2002a; Kuhn et al., 2007). Here we apply the SCM to conduct an analysis of boundary layer VOCs, $\mathrm{NO}_{\mathrm{x}}$ and ozone exchanges over the Guyana tropical forests with a particular emphasis on the role of daytime and nocturnal turbulent transport. This focus is based on the hypothesis that interpretation of the late morning and afternoon observations of compounds with lifetimes of hours and longer, e.g., the oxygenated VOCs methanol and acetone, the isoprene oxidation products methyl vinyl ketone (MVK), methacrolein (MACR), formaldehyde ( $\mathrm{HCHO}), \mathrm{NO}_{\mathrm{x}}$ and $\mathrm{O}_{3}$, requires a critical assessment of the nocturnal and early morning turbulent transport regime in the stable boundary layer and overlaying residual layer.

This study with a focus on VOC, $\mathrm{NO}_{\mathrm{x}}$ and $\mathrm{O}_{3}$ complements an analysis by Stickler et al. (2007) who compared results of chemical box simulations with the GABRIEL observations focusing on carbon monoxide (CO), $\mathrm{HCHO}$ and hydrogen peroxide $\left(\mathrm{H}_{2} \mathrm{O}_{2}\right)$. In their analysis, which does not explicitly treat the role of turbulent mixing in the boundary layer (but includes the contribution by entrainment of free troposphere air masses), the role of $\mathrm{HCHO}, \mathrm{H}_{2} \mathrm{O}_{2}$ and organic peroxides dry deposition has been addressed using dry deposition calculations of the SCM. Here we discuss in greater detail the dry deposition process as well as other relevant surface and boundary layer processes including the role of soil moisture. This parameter is not only a key controlling factor in the boundary layer development and, consequently, tracer transport but through its role in dry deposition and biogenic emissions as encountered during GABRIEL.

One particular aim of the presented analysis is to use the observations to improve particular features of the representation of surface and boundary layer reactive trace gas exchanges in atmospheric chemistry models. On the other hand, the model analysis provides complementary information required for the interpretation of the observations through state-of-the-art simulations of processes and parameters which have not been measured.

More details about the measurements that have been used in the here presented evaluation, including the concentration measurements of VOC's, $\mathrm{NO}_{\mathrm{x}}, \mathrm{O}_{3}$ and $\mathrm{HO}_{\mathrm{x}}$ are provided by Eerdekens et al. (2008), Stickler et al. (2007) and Martinez et al. (2008). Details about the SCM simulations relevant to the analysis are presented in Sect. 2, followed by an evaluation of the meteorological drivers of surface and boundary layer reactive trace gas exchanges in Sect. 3. The exchanges of methanol and acetone, $\mathrm{NO}_{\mathrm{x}}$, ozone, isoprene and the oxidation products as well as an evaluation of the radical chemistry simulations, including the potential role of reactive terpenes, are discussed in Sect. 4. This is followed by a discussion in Sect. 5 that in particular addresses the role of the nocturnal-, early morning transition- and daytime exchanges regimes, and Sect. 6 presents the conclusions.

\section{Single-column chemistry and climate model}

Our evaluation of the sources and sinks of reactive trace gases in the Guyana boundary layer is based on simulations conducted with the single-column version of the chemistry and climate model ECHAM4 (Ganzeveld et al., 2002a, 2006b). In the default set-up the SCM has 19 vertical layers (referred to as L19 version) up to $10 \mathrm{hPa}$ with a Surface Layer (SL) depth of about $65 \mathrm{~m}$ and increasing depth of the layers aloft with generally 5 layers representing the daytime convective boundary layer (BL) up to about $1500 \mathrm{~m}$ altitude. Prognostic variables are temperature, surface pressure, humidity and cloud water and the SCM contains parameterizations of radiation, cloud formation and precipitation, convection and vertical diffusion. Land surface processes are described by a 5-layer heat conductivity soil model and by a hydrological model. Over land, each grid square is subdivided into 4 fractions to distinguish between snow coverage, bare soil, water in the skin reservoir and dry vegetation. The evapotranspiration for the latter fraction is calculated from the stomatal resistance (Sellers et al., 1986) as a function of surface radiation, soil moisture and Leaf Area Index (LAI). 
One feature of the SCM is that it allows for an analysis of the response of the meteorology and atmospheric chemistry to changes in surface cover by advecting the column along a prescribed transect (Ganzeveld and Lelieveld, 2004). This approach is only valid if wind shear is minor, as indicated by small changes in wind speed and direction with altitude. The observations indeed indicate little wind shear within the boundary layer (BL) and lower free troposphere up to about $2 \mathrm{~km}$ altitude, which is the main domain of interest in this study. We study the atmospheric column processes during the ocean-land transition moving westward from the Atlantic Ocean, northeast of South America, over the tropical forests of French Guyana and Suriname following the easterly October trade winds. We show the results of a simulation, moving the column at $4.5^{\circ} \mathrm{N}$ from its initial location at $45^{\circ} \mathrm{W}$ to $60.0^{\circ} \mathrm{W}$, from 1 st October, 21:00 LT (00:00 GMT) and the subsequent 3 days using a time step of $60 \mathrm{~s}$.

Figure 1 shows the selected transect and the GABRIEL campaign flight tracks. In the simulation the air column moves with a mean speed of about $6.5 \mathrm{~m} \mathrm{~s}^{-1}$ reflecting a marine atmospheric chemistry regime over the Atlantic Ocean for the first day (2 October), reaching the coast of French Guyana around 05:00 LT during the second day (3 October) with the air mass composition then changing in response to the transport over the coastal region and the tropical forest inland. The simulation continues for one more day (4 October) to also include a continental day-night-day transition to study the significance of the nocturnal tropical forest exchange regime for daytime atmospheric chemistry and exchanges. Note that the results for 4th October reflect simulations of the continental boundary layer development west of $\sim 57^{\circ} \mathrm{W}$ whereas the observations are mostly confined to the domain east of this longitude (Fig. 1). Therefore, the comparison of model simulations with observations focuses on the results for 3rd October. The column has been initialized with temperature, moisture and wind speed profiles simulated with the global ECHAM4 version, and tracer mixing ratios are initialized with vertical profiles from the chemistry and tracer transport model TM3 (Houweling et al., 1998) with some modifications to simulate vertical profiles over the ocean in close agreement with the observations.

To ensure that the representation of meteorology is comparable to the actual conditions during GABRIEL, we have applied the ECMWF analyzed meteorology for 1st October, 2005 , of the ECMWF model grid cell $4.5^{\circ} \mathrm{N}$ and $45^{\circ} \mathrm{W}$, and nudge the simulated meteorology over the ocean for the first $24 \mathrm{~h}$ of the simulation (Ganzeveld et al., 2006a). Surface properties such as the vegetation fraction and soil moisture are prescribed to the column along the transect based on a global ECHAM4 model simulation. These surface properties are complemented with vegetation cover parameters including LAI and surface roughness, being inferred from the Olson (1992) ecosystem database and normalized differential vegetation index (NDVI) observations (Ganzeveld et al., $2002 \mathrm{~b}$ ). In contrast to a previous analysis of the impact of

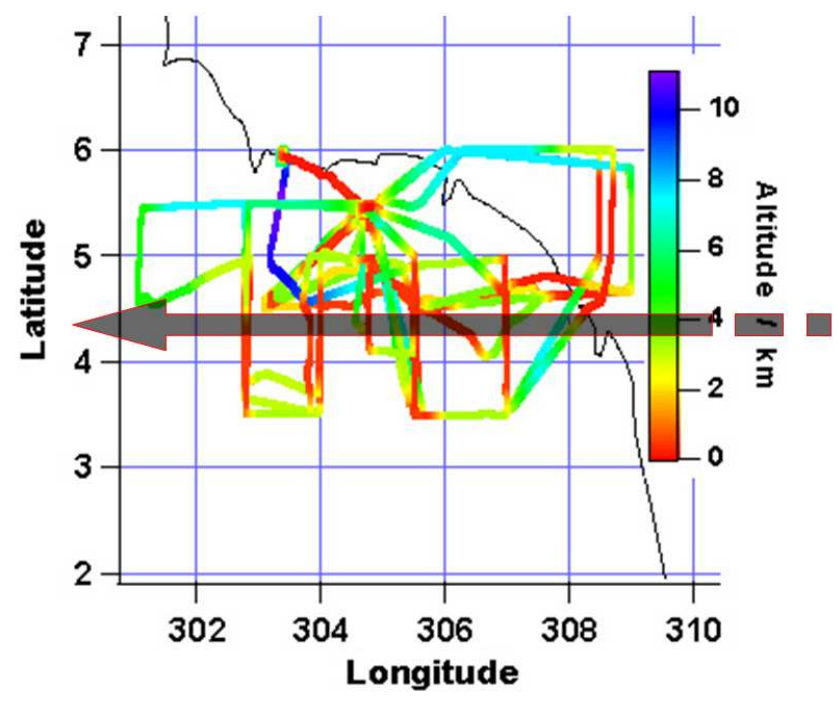

Fig. 1. Transect along which the SCM has been advected by a wind speed of $6.5 \mathrm{~m} \mathrm{~s}^{-1}$ for a reference height of $1250 \mathrm{~m}$, from $45^{\circ}$ to $60^{\circ} \mathrm{W}$ along $4.5^{\circ} \mathrm{N}$. The duration of the simulation is 3 days using a time step of $60 \mathrm{~s}$, which represents a distance per time step of $\sim 300 \mathrm{~m}$. Also shown are the measurement flight tracks with the colors indicating altitude.

tropical deforestation on the atmospheric chemistry applying the "big-leaf" approach (Ganzeveld and Lelieveld, 2004), we apply for this evaluation the detailed multi-layer model for reactive trace gas exchanges. This warrants the explicit simulation of the diurnal cycle in atmosphere-biosphere exchange fluxes, leading to a peak in the biogenic $\mathrm{NO}_{\mathrm{x}}$ flux in the early morning associated with the nocturnal accumulation of $\mathrm{NO}_{\mathrm{x}}$ inside the canopy due to the continuous soil NO emissions.

The within-canopy and atmospheric gas-phase chemistry is based on an implementation of the carbon bond mechanism version 4 (CBM4) according to Roelofs and Lelieveld (2000). The scheme considers the standard background methane oxidation reactions, as well as non-methane hydrocarbons including isoprene $\left(\mathrm{C}_{5} \mathrm{H}_{8}\right)$, a selection of hydrocarbon oxidation products such as aldehydes and ketones and has been modified to include the first-order contribution of the oxidation of terpenes, including ozonolysis, and oxidation products relevant to peroxide chemistry and exchanges (Ganzeveld et al., 2006b). Note that the extra source of $\mathrm{HO}_{\mathrm{x}}$ in the isoprene oxidation mechanism according to Lelieveld et al. (2008) and Butler et al. (2008) has not been considered in the default setup of the SCM in this study but it will be considered in follow-up analyses through inclusion of a modified gas-phase chemistry scheme in the SCM. The here presented analysis is mainly limited to a detailed discussion of the sources, sinks and transport of $\mathrm{HO}_{\mathrm{x}}$ precursors and associated discrepancies in simulated tropical $\mathrm{HO}_{\mathrm{x}}$ concentrations in the SCM and any large-scale atmospheric chemistry model that uses comparable state-of-the art gas-phase chemistry implementations. 

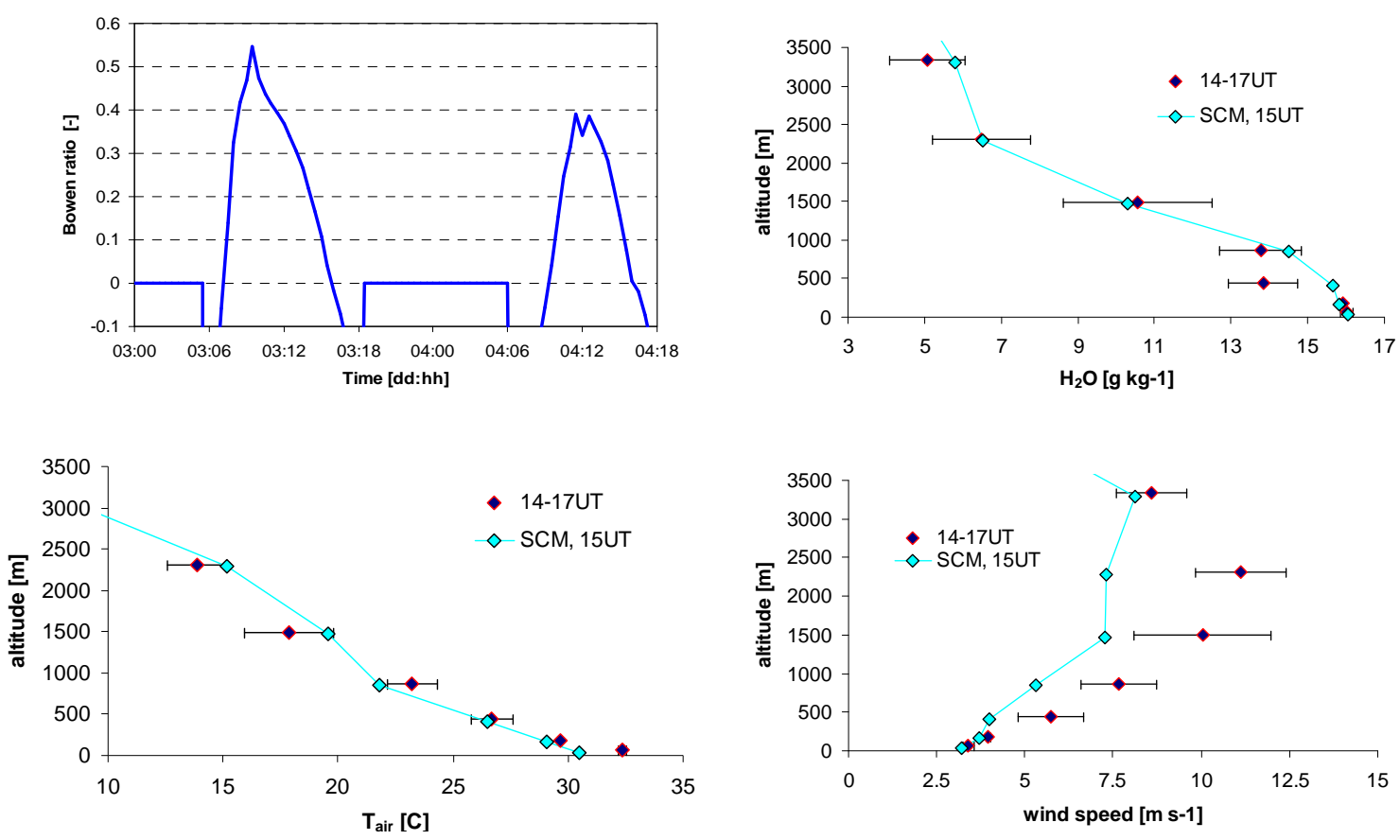

Fig. 2. Evaluation of micro- and BL meteorology. Figure 2a shows the simulated Bowen ratio for 3-4 October with a daytime average over land of $\sim 0.13$. Figure $2 \mathrm{~b}$ shows the comparison of the simulated versus observed water vapor profiles $\left(\mathrm{g} \mathrm{kg}^{-1}\right)$ over land up to $3.5 \mathrm{~km}$ altitude. The observed water vapor reflects the average and standard deviation of all measurements collected between 4.5 and $5.5^{\circ} \mathrm{N}$ and $52-56^{\circ} \mathrm{W}$ for 14:00-17:00 UT. The simulated profile refers to 3rd October at 15:00 UT (12:00 LT). Figures 2c and d, as 2b but for air temperature and wind speed, respectively.

The results reflect, unless indicated differently, simulations with the SCM using the L19 model resolution also motivated by the fact that this resolution resembles that of the troposphere in the global chemistry-climate model ECHAM5/MESSy used to study in detail the contribution of long-range transport and isoprene oxidation chemistry (Butler et al., 2008). To additionally address the sensitivity of the simulated trace gas mixing ratios to the model representation of turbulent transport we also include model simulations using the ECMWF 60-layer model resolution (L60), with an SL depth of $\sim 20 \mathrm{~m}$ and a lower $1500 \mathrm{~m}$ domain representation by 13 instead of 5 layers.

\section{Evaluation of simulated boundary layer meteorology}

Evaluation of various chemically reactive species with different sources and sinks and chemical lifetimes facilitates the testing of our understanding of processes involved in tropical boundary layer reactive trace gas exchanges. A prerequisite for a fair evaluation of the sources and sinks of reactive trace gases in the BL is the representation of micrometeorology, the BL evolution and turbulent transport. The SCM and the global climate model ECHAM4 (and ECHAM5/MESSy) often simulate a too shallow boundary layer over tropical forests, especially during the wet season. One of the main reasons for the underestimation of the BL height is a misrep- resentation of the surface energy balance for tropical forests (Ganzeveld et al., 2002a) with too much energy being used for evapotranspiration resulting in a significant underestimation of the surface sensible heat flux. Possible explanations for a too large simulated tropical forest evapotranspiration include the model representation of stomatal exchange and convective rainfall interception (Dolman and Gregory, 1992) although it is beyond the scope of this study to address these aspects in detail.

For the analysis presented here, focusing on atmospheric chemistry, we have ensured a realistic representation of the surface energy balance and BL depth by prescribing soil moisture such that the soil moisture stress function $\left(\mathrm{F}_{w s}\right)$ has a value of 0.5 . In the SCM (and also ECHAM4/5) this parameter describes the dependence of stomatal exchange (Sellers, 1986, 1989) on soil moisture and this imposed constraint results in a simulated stomatal resistance twice as large as the resistance for soil moisture at the field capacity. Unfortunately the actual soil moisture status and its impact on the surface energy and water vapor exchanges encountered during GABRIEL can not be evaluated by comparison with observations. However, for $\mathrm{F}_{w s}=0.5$ the simulated daytime median of the ratio of the sensible to latent heat flux, the socalled Bowen ratio, which is shown in Fig. 2a for 3-4 October, of $\sim 0.15$ is comparable to that observed in other tropical forest sites by da Rocha et al. (2004) (note that the daytime average is negative due to the large negative values in the 
early morning and late afternoon). In addition, the simulated maximum BL depth, which depends among other variables also on surface energy partitioning, of about $1400 \mathrm{~m}$ agrees well with the observed BL depth $(\sim 1440 \mathrm{~m})$. The latter has been inferred from observed virtual temperature profiles determining the first temperature inversion in those profiles going upward (Eerdekens et al., 2008) and is about $\sim 300 \mathrm{~m}$ deeper compared to the simulated $\mathrm{BL}$ height taking $\mathrm{F}_{w s}=1$ (no soil moisture stress).

Despite the fact that GABRIEL was conducted during the dry season, meteorological observations indicate that the region was still relatively moist with daily rain showers subsequent to the development of shallow cumulus convection in the afternoon. The shallow cumulus clouds, with a cover ranging between $1 / 8-3 / 8$, were generally present between $1-$ $3 \mathrm{~km}$ altitude and complicate inferring emission fluxes from observed mixing ratios in the BL as presented by Eerdekens et al. (2008). The inferred emission fluxes include an uncertainty range that reflects, in addition to the uncertainty associated with chemistry and entrainment (Eerdekens et al., 2008), the difference between the BL depth and a deeper volume in which the actual tracer mixing occurs referred to as the mixed layer (ML) depth. The virtual temperature profiles do not always show such an explicit inversion (indicated by a large jump in temperature, moisture and tracer mixing ratios at the inversion zone) as is generally found at the top of clear sky boundary layers. The available moisture results in the occurrence of a conditionally unstable layer where shallow cumulus clouds form above the first virtual temperature inversion (BL height) in which tracer transport occurs thereby further decreasing the BL mixing ratios of emitted compounds. In order to assess the possible consequences of this enhanced mixing mechanism for the inferred surface emissions we have estimated the ML depth based on BL height, cloud top height, cloud cover and lifetime of the chemical compound. With a cloud cover of $2 / 8-3 / 8$ and an assumed maximum cloud top height of $3 \mathrm{~km}$, the area- average ML depth is $\sim 1900 \mathrm{~m}$, which actually agrees quite well with the area-average altitude of the observed second virtual temperature inversion. This difference of $\sim 400 \mathrm{~m}$ between the ML and BL depth has been applied to estimate the uncertainty in the emission fluxes. Numerical analysis by VilàGuerau de Arellano and van den Dries (2008) suggests that the significance of this enhanced upward transport in the conditionally unstable layer above the BL, and the uncertainty in inferred emissions, decreases with a decrease in lifetime of emitted species. Consequently, this enhanced mixing process is expected to be less relevant for isoprene compared to longer lived compounds such as methanol and acetone.

The SCM actually simulates the development of cumulus clouds, with a maximum cloud cover up to $\sim 4 / 8$ but the cloud base is simulated to be around $3 \mathrm{~km}$ altitude. The consequences of this simulated representation of clouds for photolysis and convective transport are discussed in more detail in Sect. 4. Figure $2 b$ shows a comparison of the observed average water vapor profile over land for 14:00-17:00 UT (11:00-14:00 LT), and the simulated profile for 3rd October, 15:00 UT. The comparison shows that the model, with the imposed significant decrease in evapotranspiration, reproduces the water vapor content in and above the BL generally well. The model also simulates the observed air temperature well, shown in Fig. 2c, with respect to the profile and the absolute values, although there is a difference between the maximum simulated and observed SL temperature of about $2 \mathrm{~K}$. This might reflect a low-altitude measurement bias of conditions at and near the airport as well as a model discrepancy. A comparison of wind speed profiles, shown in Fig. 2d, indicates that the simulated surface wind speed is in good agreement with the observations suggesting that the role of turbulence in atmosphere-biosphere exchanges is represented well in the model. However, it can be clearly seen that the model simulates a too small increase in wind speed with altitude in the BL which points at a misrepresentation of momentum fluxes. This underestimation of wind speed at the top of the BL has consequences for the simulated exchanges of trace gases between the BL and free troposphere. An indication about the accuracy of model simulated radiative fluxes, another driver of reactive trace gas exchanges and atmospheric chemistry, will be presented later in Sect. 4.2 since the radiation measurements were limited to the photolysis frequency of $\mathrm{NO}_{2}\left(\mathrm{jNO}_{2}\right)$.

\section{Reactive trace gas exchanges}

The observations indicate that the conditions for the photochemistry encountered during GABRIEL reflect the role of natural emissions with only occasional, local contributions by anthropogenic and biomass burning emissions. Consequently, an interpretation of the observed reactive trace gas concentrations requires a thorough evaluation of natural sources, sinks and transport of precursors involved in the photochemistry over the forest in the Guyanas, which involves soil-biogenic $\mathrm{NO}_{\mathrm{x}}$ exchanges, biogenic emissions of VOCs and oxygenated species as well as dry deposition of species such as ozone and oxidation products.

As indicated above, the soil moisture has been modified in the SCM simulations for a realistic representation of the boundary layer evolution. To evaluate the simulations of turbulent tracer transport in the BL and between the BL and the free troposphere (FT) we first present an evaluation of the methanol and acetone exchanges and concentrations. An advantage of interpreting these compounds is that, due to their relatively long chemical lifetimes, chemical transformations do not play a significant role at the timescale of BL turbulent transport but a major limiting aspect of this interpretation is the lack of knowledge about their biogenic sources and sinks. Probably the latter have been better quantified for reactive nitrogen oxides and ozone. However, the exchange of $\mathrm{NO}_{\mathrm{x}}$ and $\mathrm{O}_{3}$ is also affected by chemical 


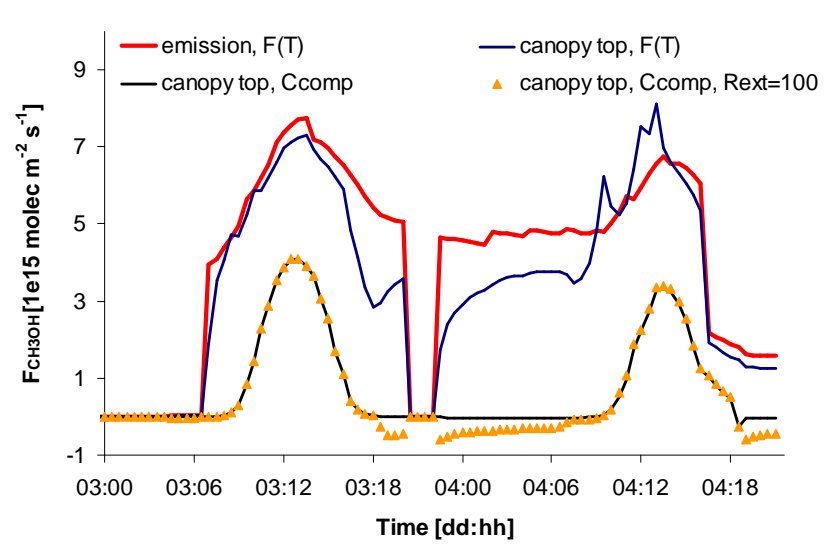

Fig. 3. Simulated biogenic emission and canopy-top $\mathrm{CH}_{3} \mathrm{OH}$ flux $\left(10^{15}\right.$ molecules $\left.\mathrm{m}^{-2} \mathrm{~s}^{-1}\right)$ for 3-4 October according to the implementation by Lathière et al. (2006) with the red and dark blue line showing the emission and canopy-top flux, respectively. The zero fluxes during the night of 3-4 October indicate the passage of the column over lake Brokopondo. The black line shows the simulated canopy-top flux for the compensation point approach implemented in the SCM with a maximum flux for 3rd October of about $4.2 \times 10^{15}$ molecules $\mathrm{m}^{-2} \mathrm{~s}^{-1}$ comparable to the observed emission flux. The orange triangles show the simulated canopy top fluxes for the compensation point approach and an enhanced nocturnal removal efficiency using an $\mathrm{R}_{\text {ext }}$ of $100 \mathrm{~s} \mathrm{~m}^{-1}$.

interactions including the reactive VOC species such as isoprene and terpenes, thus complicating the evaluation of $\mathrm{BL}$ turbulent transport of these components.

\subsection{Oxygenated compounds: methanol and acetone}

Observations suggest that atmosphere-biosphere exchanges of the oxygenated compounds methanol and acetone are influenced by a canopy-scale compensation point $\left(\mathrm{C}_{\text {comp }}\right)$ with upward or emission fluxes for surface layer concentrations smaller than $\mathrm{C}_{\text {comp }}$ and downward or dry deposition fluxes for surface layer concentrations larger than $\mathrm{C}_{\mathrm{comp}}$. For example, observations above and within a Costa Rica tropical forest by Karl et al. (2004) showed daytime emission fluxes for methanol and acetone of $\sim 2.6 \times 10^{15}$ molecules $\mathrm{m}^{-2} \mathrm{~s}^{-1}$ and $1 \times 10^{15}$ molecules $\mathrm{m}^{-2} \mathrm{~s}^{-1}$, respectively, whereas the nocturnal gradient measurements indicated the presence of a canopy sink. As a possible explanation for this sink Karl et al. (2004) proposed deposition to leaves enhanced by the formation of dew. In contrast, Harley et al. (2007) conducted leaf enclosure measurements that showed generally small or near zero nocturnal methanol emissions. During GABRIEL, no direct flux measurements were conducted although observed surface concentration changes at Brownsberg suggest a similar bi-directional exchange regime. The inferred daytime $\mathrm{CH}_{3} \mathrm{OH}$ and acetone emission fluxes for an observed $\mathrm{BL}$ height of $\sim 1400 \mathrm{~m}$ are $\sim 4.2 \times 10^{15}$ molecules $\mathrm{m}^{-2} \mathrm{~s}^{-1} \quad(0.80 \mathrm{mg}$
$\left.\mathrm{CH}_{3} \mathrm{OH} \mathrm{m}^{-2} \mathrm{~h}^{-1}\right) \quad$ and $\quad \sim 1 \times 10^{15}$ molecules $\mathrm{m}^{-2} \mathrm{~s}^{-1}$ $\left(0.35 \mathrm{mg}\right.$ Aceton $\left.\mathrm{m}^{-2} \mathrm{~h}^{-1}\right)$, respectively (Eerdekens et al., 2008). Inferring the magnitude of the removal fluxes at night is unfortunately not possible because observations of the nocturnal turbulent mixing conditions at the Brownsberg site were not performed. The observed concentration decreases suggest, similar to the observations by Karl et al. (2004), an efficient sink of methanol and acetone possibly through surface deposition. However, a role of advection in explaining the observed decreases in the concentrations can not be excluded but if the sink would indeed be dominated by surface deposition, the inferred removal rate (assuming a nocturnal inversion layer of $200 \mathrm{~m}$ ) is rather close to the turbulent limit suggesting a very efficient uptake at the surface.

A parameterization of biogenic methanol and acetone emissions, implemented in the dynamic global vegetation model (DGVM) ORCHIDEE, according to Lathière et al. (2006), does not consider this compensation point and excludes the stomatal control of emissions (see below). In this DGVM, emissions of methanol and acetone are simulated according to Guenther et al. (1995) from the foliar density (dm), an ecosystem specific emission factor and surface temperature. However, using the ORCHIDEE methanol and acetone emission factor for tropical forests of 0.6 and $0.29 \mu \mathrm{gC} \mathrm{gdm}^{-1} \mathrm{hr}^{-1}$, respectively, the SCM's foliar density of about $1200-1300 \mathrm{~g}$ for the transect and the temperature attenuation function (based on Guenther et al., 1995), we simulate unrealistically high methanol and acetone surface layer mixing ratios. Including a correction factor for mature and old leaf methanol emissions (decrease by factor of 2), as assumed by Lathière et al. (2006), still results in the simulation of maximum methanol mixing ratios in the middle of the BL up to 8 ppbv for 3 rd and 15 ppbv for 4 th October. These results are consistent with simulated $\mathrm{CH}_{3} \mathrm{OH}$ surface mixing ratios between 10 and $25 \mathrm{ppbv}$ in the global chemistryclimate model LMDz-INCA which uses ORCHIDEE to simulate biogenic emissions (Folberth et al., 2006). In contrast, the maximum observed $\mathrm{CH}_{3} \mathrm{OH}$ mixing ratio during GABRIEL, at about $300 \mathrm{~m}$ altitude and higher, is $\sim 3$ ppbv (Eerdekens et al., 2008). The simulated overestimation of $\mathrm{CH}_{3} \mathrm{OH}$ mixing ratios and increasing mixing ratios further inland also reflect a large nocturnal accumulation due to continuous temperature dependent emissions in a shallow stable boundary layer. This is illustrated in Fig. 3 which shows the simulated $\mathrm{CH}_{3} \mathrm{OH}$ emission over land and canopy top fluxes for 3-4 October. The simulated maximum $\mathrm{CH}_{3} \mathrm{OH}$ emission flux of about $8 \times 10^{15}$ molecules $\mathrm{m}^{-2} \mathrm{~s}^{-1}$ as well as the maximum acetone emission flux of $2.7 \times 10^{15}$ molecules $\mathrm{m}^{-2} \mathrm{~s}^{-1}$ (not shown here), is a factor of $\sim 3$ larger compared to the Karl et al. (2004) and GABRIEL observations. The maximum canopy top fluxes are even larger in the early morning of the second day reflecting the canopy release of methanol and acetone after accumulation within the canopy during the night. It is apparent that this parameterization, implemented 
in one of the more commonly applied DGVMs in globalscale analyses, does not simulate realistic mixing ratios both in terms of magnitude and the diurnal cycle.

The multi-layer canopy model for reactive trace gas exchanges implemented in the SCM has previously been applied to study bi-directional atmosphere-biosphere $\mathrm{NO}_{\mathrm{x}}$ exchanges including the potentially important role of an $\mathrm{NO}_{2}$ compensation point (Ganzeveld et al., 2002b). For the analysis presented here we apply the compensation point approach to also simulate the bi-directional exchanges of acetone and methanol, including stomatal control. This is based on studies that focused on methanol emissions by Hüve et al. (2007) and Harley et al. (2007, and references therein) making the assumption that the controlling mechanism of biogenic acetone emissions is similar to that of methanol. The mechanism is actually considered in a leaf exchanges model, developed by Niinemets and Reichstien (2003), being constrained with enclosure observations to study the model performance in simulating methanol emissions for a selection of vegetation types (Harley et al., 2007). However, also due to a large uncertainty in key parameters, e.g., production rate as well as the lack of observations of parameters to constrain the leaf exchanges model, we have applied a simplified approach to study the role of the diurnal cycle in acetone and methanol exchanges over tropical forests. We prescribe a non-zero stomatal concentration $\left(\mathrm{C}_{\text {stomatal }}\right)$ in the SCM multi-layer exchange calculations such that we simulate a maximum daytime emission flux comparable to the observed fluxes. Including this stomatal control on $\mathrm{CH}_{3} \mathrm{OH}$ and acetone exchange fluxes, the simulated nocturnal stomatal closure results in the simulation of nocturnal removal determined by the turbulent and quasi-laminar transport to the surface and subsequent surface uptake. In the SCM (and ECHAM5/MESSy) dry deposition of gases, for which flux observations are hardly available, the surface uptake efficiency is estimated according to an approach by Wesely (1989) based on solubility and reactivity, and scaled with the ozone and sulfur dioxide surface uptake resistances. Using a Henry coefficient of $2.2 \times 10^{2}$ and $30 \mathrm{M} \mathrm{atm}^{-1}$ for methanol and acetone, respectively, a medium reactivity for both components and $\mathrm{R}_{l u}=10^{4}$ (Wesely, 1989; Walmsey and Wesely, 1996), nocturnal removal is estimated to be small also due to inferred large uptake resistances for the dry cuticle and wet skin fraction (wet vegetation and soil due to rainfall interception or dewfall).

Figure 4 shows the simulated mixing ratios of methanol and acetone, respectively, for 3-4 October along the transect for the five layers that represent the Surface Layer (SL) up to the top of the BL around $1500 \mathrm{~m}$. The difference in $\mathrm{CH}_{3} \mathrm{OH}$ mixing ratios between the surface layer and those at $1500 \mathrm{~m}$ before sunrise at 3rd October partly reflect the used initial profiles, which are based on observed $\mathrm{CH}_{3} \mathrm{OH}$ mixing ratios over the Atlantic ocean, and simulated exchanges between the MBL and free troposphere for 1-2 October. The model simulates an increase after sunrise on 3rd
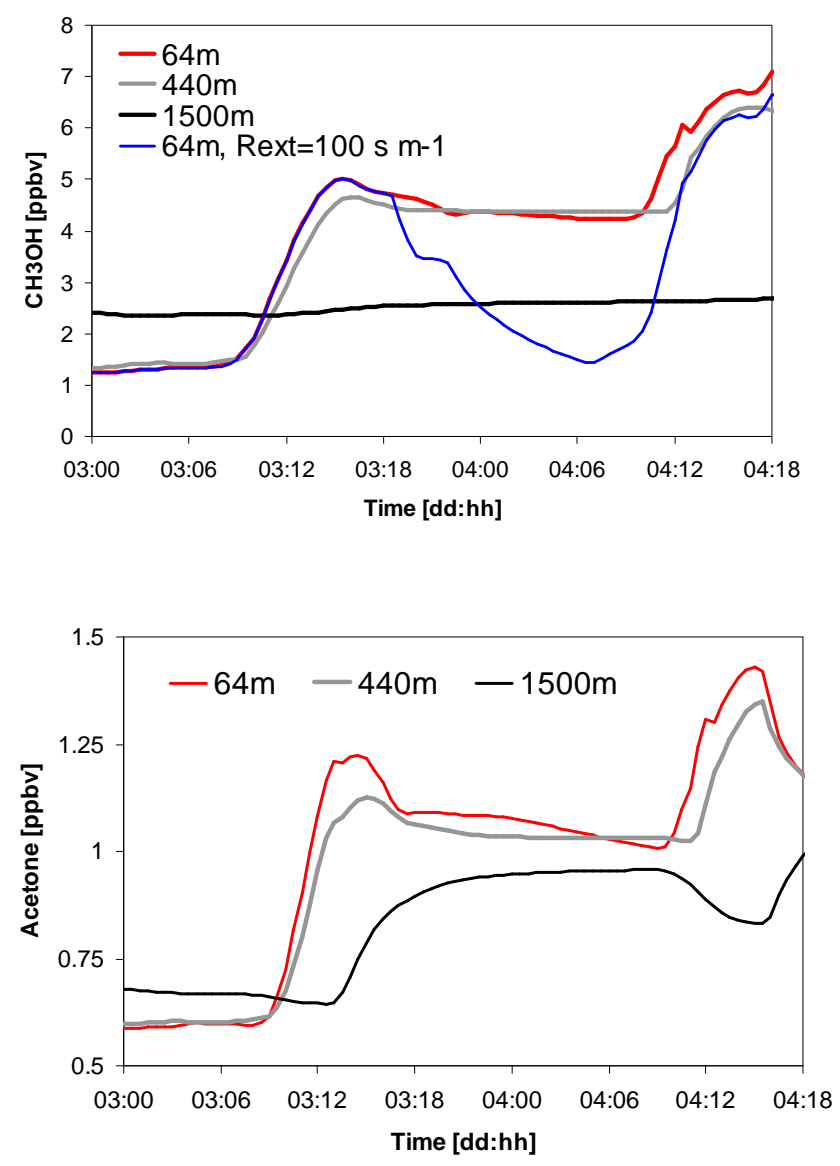

Fig. 4. Simulated $\mathrm{CH}_{3} \mathrm{OH}$ and acetone mixing ratios (ppbv) for $3-$ 4 October over land for the compensation point approach with the thick red, grey and black line showing the mixing ratios in the SL, at $\sim 440 \mathrm{~m}$ and around the top of the CBL, respectively. The blue line in Fig. 4a shows the simulated SL mixing ratio of $\mathrm{CH}_{3} \mathrm{OH}$ for an enhanced nocturnal removal efficiency using $\mathrm{R}_{\mathrm{ext}}=100 \mathrm{~s} \mathrm{~m}^{-1}$.

October from about 1.5 up to 4 ppbv $\mathrm{CH}_{3} \mathrm{OH}$ and from 0.6 to $1.25 \mathrm{ppbv}$ acetone throughout the $\mathrm{BL}$. These mixing ratios are slightly higher compared to observed mixing ratios which increase from $\sim 0.75$ to $\sim 3 \mathrm{ppbv} \mathrm{CH}_{3} \mathrm{OH}$ and $\sim 0.4$ to $\sim 1$ ppbv acetone (Eerdekens et al., 2008) while the gradients compare well. The model simulates a further increase in mixing ratio as the column moves further inland also because the nocturnal mixing ratios show, in contrast to observations, only a relatively small decrease due to surface deposition. Therefore, we have conducted an alternative simulation in which we have applied a significantly smaller nocturnal uptake resistance $\left(\mathrm{R}_{\mathrm{ext}}\right.$, mostly reflecting the uptake by the dry and wet cuticula) of $100 \mathrm{~s} \mathrm{~m}^{-1}$. The blue line in Fig. 4a shows a strong decrease in the nocturnal $\mathrm{CH}_{3} \mathrm{OH}$ mixing ratios, consistent with the observations at Brownsberg and those by Karl et al. (2004), though confined to the SL (and canopy, not shown here) reflecting the suppressed turbulent transport between the canopy, SL and layers aloft. 

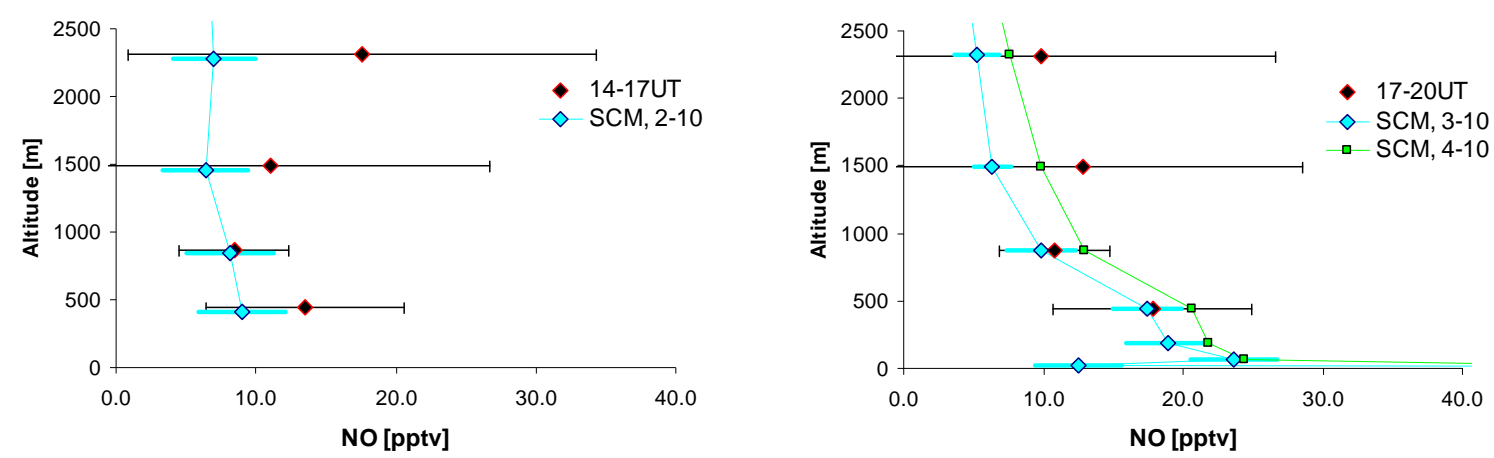

Fig. 5. Simulated and observed NO mixing ratio (pptv) profiles over the ocean from about 440-2500 m altitude, on 2nd October 14:0017:00 UT (a) and over land, 17:00-20:00 UT for 3-4 October (b) also including the mixing ratios below $440 \mathrm{~m}$ including the canopy mixing ratios which actually reach a maximum up to $\sim 200 \mathrm{pptv}$ in the canopy-soil layer.

Although the model simulates a smaller emission flux for the second day over land (4th October), the increase in $\mathrm{CH}_{3} \mathrm{OH}$ mixing ratio is larger compared to the previous day also due to the entrainment of air masses from the residual layer with, according to the model, relative high $\mathrm{CH}_{3} \mathrm{OH}$ mixing ratios. This may point at a possible misrepresentation of the nocturnal depletion in the residual layer. This feature will be further discussed after the evaluation of other components. For a more detailed comparison including a comparison of simulated and observed vertical mixing ratio profiles we refer to Eerdekens et al. (2008).

Finally, to indicate the possible decrease in the tropical forest source strength of methanol and acetone according to the ORCHIDEE implementation, the integrated $\mathrm{CH}_{3} \mathrm{OH}$ and acetone canopy-top fluxes for the compensation point approach are about $80 \%$ smaller compared to the ORCHIDEE exchange fluxes due to the substantially smaller maximum daytime fluxes and small nocturnal deposition fluxes instead of emissions. This implies that, if these findings are representative for tropical forest, the global biogenic emission budget for methanol and acetone of 106 and $42 \mathrm{TgC} \mathrm{yr}^{-1}$, as estimated by Lathière et al. (2006), would be lower by about $25(\sim 25 \%)$ and $16(\sim 40 \%) \mathrm{TgC} \mathrm{yr}^{-1}$, respectively.

\subsection{Nitrogen oxides and ozone}

The GABRIEL airborne observations include $\mathrm{NO}$ and $\mathrm{O}_{3}$ concentrations and $\mathrm{NO}_{2}$ photolysis rates. Surface observations are unfortunately not available which implies that evaluation of the boundary layer $\mathrm{NO}_{\mathrm{x}}-\mathrm{O}_{3}$ relies on the comparison of the observed and simulated $\mathrm{NO}-\mathrm{O}_{3}$ concentrations that reflect the modeled atmosphere-biosphere exchanges. The latter have been extensively evaluated earlier using the SCM in a direct comparison with observations of tropical forest exchanges (e.g., Ganzeveld et al., 2002a). Comparison of simulated and observed $\mathrm{BL}$ and free troposphere $\mathrm{NO}$ and $\mathrm{O}_{3}$ mixing ratios as well as the $\mathrm{NO}_{2}$ photolysis rates should pose important constraints on the $\mathrm{NO}_{\mathrm{x}}-\mathrm{O}_{3}$ photochemistry and transport processes. Figures $5 \mathrm{a}$ and $\mathrm{b}$ shows a comparison of the simulated and observed average NO mixing ratio profiles over the ocean (14:00-17:00 UT) and over land up (17:0020:00 UT), respectively, up to an altitude of $2.5 \mathrm{~km}$. Occasional outliers in the observed NO mixing ratios up to more than $1 \mathrm{ppbv}$ have been excluded since these likely reflect the role of anthropogenic emissions, most likely some localized pollution sources as indicated by simultaneously enhanced $\mathrm{O}_{3}$ mixing ratios. Figure $5 \mathrm{~b}$ also shows the simulated profiles for 3-4 October to indicate the mixing ratio changes land inward. The comparison indicates that the model simulates NO mixing ratio in the BL over land in good agreement with the observations whereas over the ocean the model simulates NO mixing ratios that are generally lower than observed. This discrepancy may be explained by a significant underestimation of the simulated $\mathrm{jNO}_{2}$ (15:00 UT, 12:00 LT) over the ocean. Figure 6a shows that the observed average $\mathrm{jNO}_{2}$ in the lower $1 \mathrm{~km}$ for 14:00-17:00 UT as high as $15 \times 10^{-3} \mathrm{~s}^{-1}$ is about $30 \%$ larger compared to the simulated $\mathrm{jNO}_{2}$. The $\mathrm{SCM}^{\prime} \mathrm{j} \mathrm{jO}_{2}$ actually resembles the $\mathrm{jNO}_{2}$ simulated with the chemistry-climate model ECHAM5/MESSy over the ocean near the equator for a clear-sky global radiation flux of $\sim 1000 \mathrm{~W} \mathrm{~m}^{-2}$, a flux also simulated by the SCM for 2 nd October. This suggests that simulations of the photolysis with state-of-the-art models (ECHAM5-MESSy and the SCM use implementations based on the Landgraf and Crutzen 1998, scheme) over the tropical ocean substantially underestimate the photolysis of $\mathrm{NO}_{2}$, and possibly also the photolysis of other components, for yet unknown reasons. This may point to a role of aerosols in enhancing photolysis rates which is considered in the SCM photolysis calculations, though in a rather rudimentary way using prescribed aerosol densities (4000 particles $\mathrm{cm}^{-3}$ in the MBL) and properties (MBL scattering optical thickness of $\sim 0.02$ ). Figure $6 \mathrm{~b}$ indicates that there is actually good agreement between the observed and simulated $\mathrm{jNO}_{2}$ in the continental $\mathrm{BL}$ where the SCM captures the observed NO mixing ratio profiles well whereas the underestimation in the NO mixing ratios 

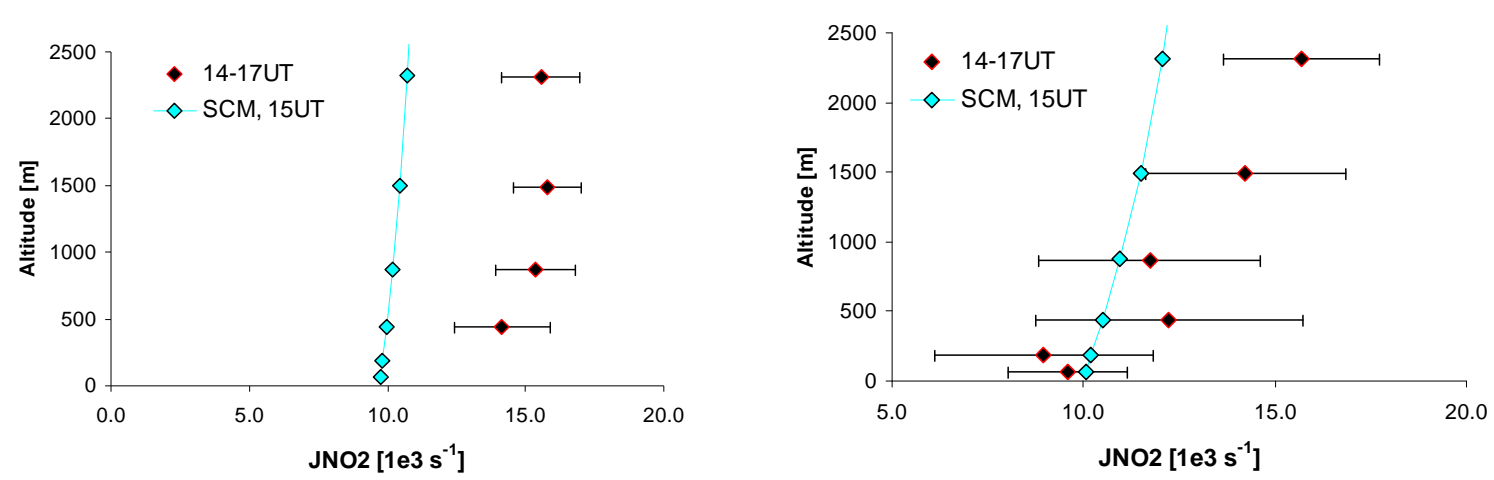

Fig. 6. Simulated and observed $\mathrm{NO}_{2}$ photolysis rates $\left(10^{3} \mathrm{~s}^{-1}\right)$ profiles over the ocean (a) and over land (b) up to $2500 \mathrm{~m}$ altitude. The observations reflect the average and standard deviation of the 14:00-17:00 UT observations whereas the simulated profiles reflect the 15:00 UT (12:00 LT) profile.

in the lower free troposphere is partly explained by an underestimation in the simulated $\mathrm{jNO}_{2}$. There are even more pronounced discrepancies higher up in the free troposphere between $2.5-6 \mathrm{~km}$ with a simulated $\mathrm{jNO}_{2}$ being about $30 \%$ lower compared to the observations, which show an enhancement of $\mathrm{jNO}_{2}$ associated with shallow cumulus cloud cover and aerosols. The SCM does not simulate clouds in the lower free troposphere for 3rd October whereas during 4th October significant cloud cover at about $3 \mathrm{~km}$ altitude results in a simulated maximum $\mathrm{jNO}_{2}\left(\sim 17 \times 10^{-3} \mathrm{~s}^{-1}\right)$, comparable to the observations above clouds.

The simulated increase in NO mixing ratios from the coast to further inland reflects simulations of soil NO emissions from wet soils based on the Yienger and Levy (1995) algorithm with a constant (no temperature dependence for emission category rainforest) wet soil emission flux for most of the domain of about $2.6 \mathrm{ng} \mathrm{m}^{-2} \mathrm{~s}^{-1}$ (in terms of mass nitrogen, $11.2 \times 10^{13}$ molecules $\mathrm{m}^{-2} \mathrm{~s}^{-1}$ ). Along the transect a few areas with agricultural activity and an area west of $59^{\circ} \mathrm{W}$ with a savannah/grass cover have slightly larger soil $\mathrm{NO}$ emission fluxes compared to that of rainforest, as shown in Fig. 7.

During GABRIEL direct NO soil emission flux measurements were not made. However, the simulated soil NO emission fluxes have been compared with laboratory measurements. These inferred soil NO fluxes were calculated using soil samples collected in the rainforest near Brownsberg according to the method of van Dijk et al. (2002). Since soil diffusivity was not measured it was estimated according to Moldrup et al. (2000). The laboratory emission estimates were fitted as a function of soil moisture, in terms of Water filled Pore space (WFPS) and temperature according to the method of Meixner and Yang (2006). The soil water filled pore space (WFPS) was determined from the modeled gravimetric soil moisture according to the method of Parton et al. (2001). A $\mathrm{Q}_{10}$ temperature dependence of 1.95 was determined using the difference in $\mathrm{NO}$ release between soils measured at $25^{\circ} \mathrm{C}$ and at $35^{\circ} \mathrm{C}$ during the peak of $\mathrm{NO}$ release

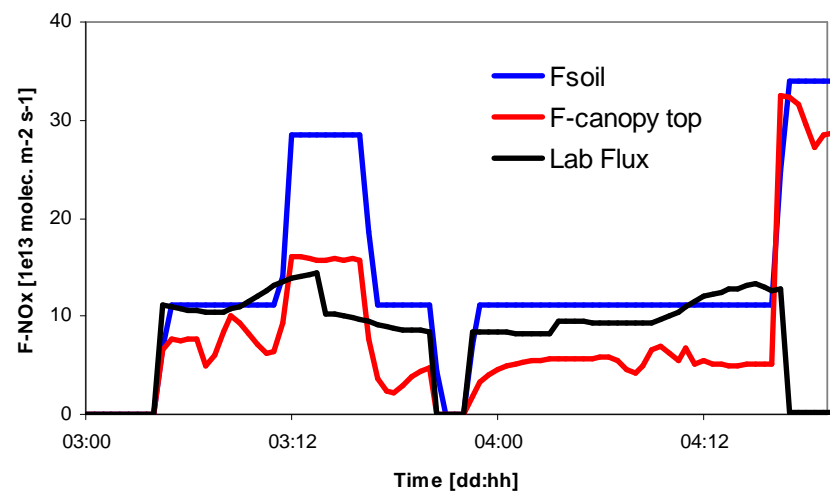

Fig. 7. Simulated soil NO (blue) and canopy-top $\mathrm{NO}_{\mathrm{x}}$ flux (red) $\left(10^{13}\right.$ molecules $\left.\mathrm{m}^{-2} \mathrm{~s}^{-1}\right)$, indicating the fraction of the soil $\mathrm{NO}$ emissions that is actually released to the atmosphere. The zero fluxes during the night of 3-4 October indicate the passage of the column over lake Brokopondo. Also shown are soil NO emission fluxes (black) based on laboratory measurements of the emissions from Suriname forest soil samples constrained with the simulated soil temperature and moisture.

(data not shown), which is within the range of the modeled soil temperatures. The optimum soil moisture for NO emission was found to be $33.3 \%$ WFPS and at $25^{\circ} \mathrm{C}$ the optimum NO flux was found to be $2.65 \mathrm{ng} \mathrm{m}^{-2} \mathrm{~s}^{-1}$. To assess how this optimum emission flux compares to the simulated $\mathrm{NO}$ emission flux we have calculated the soil NO emission flux from the SCM's WFPS and soil temperature using this laboratory measured dependency. It can be inferred from Fig. 7 that this laboratory based soil NO emission flux, constrained with the SCM soil moisture and temperature, compares well to the simulated NO emission flux for the unperturbed tropical rainforest along the transect. 

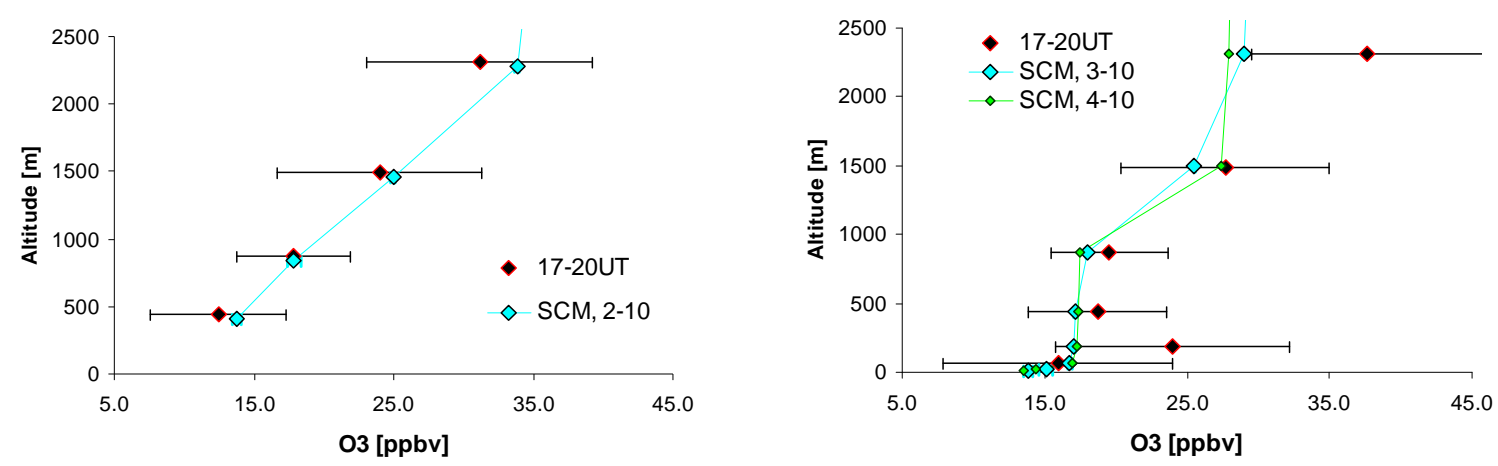

Fig. 8. Simulated and observed $\mathrm{O}_{3}$ mixing ratio (ppbv) profiles over the ocean from about 440-2500 m altitude, on 2nd October 14:0017:00 UT (a), and over land, 17:00-20:00 UT for 3 and 4 October (b) also including the mixing ratios below $440 \mathrm{~m}$.

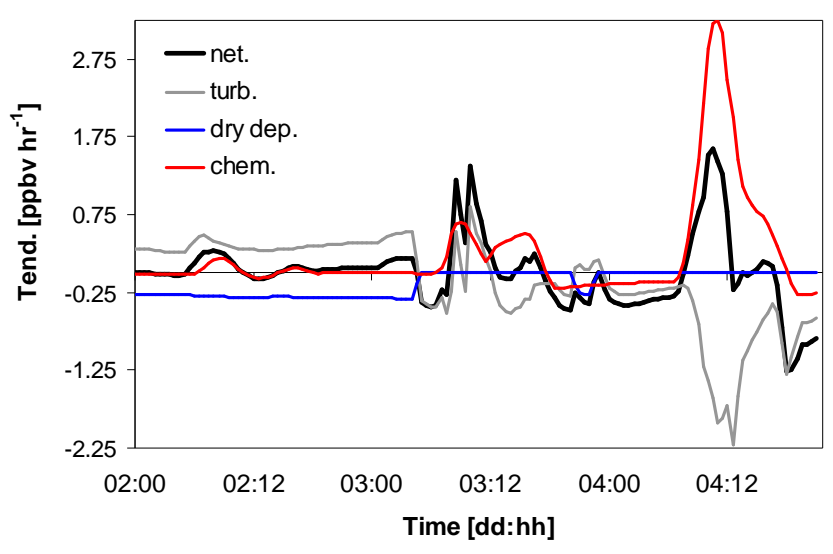

Fig. 9. Simulated surface layer net- and process tendencies $\left(\mathrm{ppbv} \mathrm{hr}{ }^{-1}\right.$ ) that control the perturbations in surface layer $\mathrm{O}_{3}$ mixing ratios from 2-4 October. "Turb" refers to the turbulent transport tendency, "dry dep" to dry deposition tendency, which equals zero over land since there the dry deposition acts upon the in-canopy and not the surface layer concentrations, and "chem" refers to the chemical production/destruction tendency.

Figure 7 furthermore indicates the fraction of the soil NO emissions expected to be released into the atmosphere by also showing the canopy top $\mathrm{NO}_{\mathrm{x}}$ fluxes. Note that zero emission fluxes during the night of 3-4 October reflect the simulated passage of the atmospheric column over lake Brokopondo. It can be inferred that, according to the multi-layer canopy model implementation in the SCM, generally about $50 \%$ or less of the soil emissions is released into the atmosphere, except for conditions dominated by savannah/grass cover (end of 4th October) with a much smaller Leaf Area Index (LAI) compared to tropical forest, so that most of the emitted $\mathrm{NO}_{\mathrm{x}}$ can escape the canopy because the removal of $\mathrm{NO}_{2}$ by dry deposition is much less than in forest conditions.

The previously discussed decrease in evapotranspiration does not only affect the simulated surface energy balance and BL depth but also the dry deposition of species being controlled by stomatal uptake, for example of ozone and $\mathrm{NO}_{2}$. The simulated maximum ozone dry deposition canopytop flux of about $3.5 \times 10^{15}$ molecules $\mathrm{m}^{-2} \mathrm{~s}^{-1}$ is in good agreement with available observations over tropical forests in Brazil (Fan et al., 1990; Rummel et al, 2007). However, these observed fluxes reflect wet season conditions with observed daytime ozone mixing ratios of $\sim 10 \mathrm{ppbv}$ compared to simulated and observed surface layer ozone mixing ratios of about $18 \mathrm{ppbv}$ during GABRIEL. The maximum simulated ozone dry deposition velocity $\left(V_{d \mathrm{O}_{3}}\right)$ of $0.8 \mathrm{~cm} \mathrm{~s}^{-1}$, calculated from the canopy-top $\mathrm{O}_{3}$ flux and surface layer mixing ratio, is substantially smaller compared to the maximum observed $V_{d \mathrm{O}_{3}}$ over tropical forest being as high as $2 \mathrm{~cm} \mathrm{~s}^{-1}$. However, the latter represents conditions without soil moisture stress and a large roughness inducing a very efficient turbulent exchange. The maximum diagnostic $V_{d \mathrm{O}_{3}}$ for $\mathrm{F}_{w s}=1$ is $1.2 \mathrm{~cm} \mathrm{~s}^{-1}$. Evaluation of the role of $\mathrm{O}_{3}$ dry deposition relative to transport, mixing and chemical production or destruction relies on the comparison of simulated and observed $\mathrm{O}_{3}$ mixing ratios during the transport of the air masses from the coast further inland.

Figure 8 shows the vertical $\mathrm{O}_{3}$ profile up to an altitude of $2.5 \mathrm{~km}$ over the ocean for 14:00-17:00 UT and over land for 17:00-20:00 UT, respectively. The good agreement between the simulated and observed profile over the ocean to a large extent reflects the selected initial vertical profiles with a relatively long lifetime due to small surface deposition and low $\mathrm{NO}_{\mathrm{x}}$ conditions. The model simulates a small increase in $\mathrm{O}_{3}$ of about 5 ppbv between the marine and continental BL. Interpretation of the profile over land is difficult due to the limited number of observations below $\sim 300 \mathrm{~m}$, also indicated by the large observed variability. Nevertheless, the simulated vertical profiles seem to be in good agreement with the observations from the surface to the BL top, clearly showing a profile that reflects the efficient surface removal by dry deposition. It is also interesting that changes in $\mathrm{O}_{3}$ between 3 and 4 October are small suggesting equilibrium between $\mathrm{BL}$ sources and sinks. 


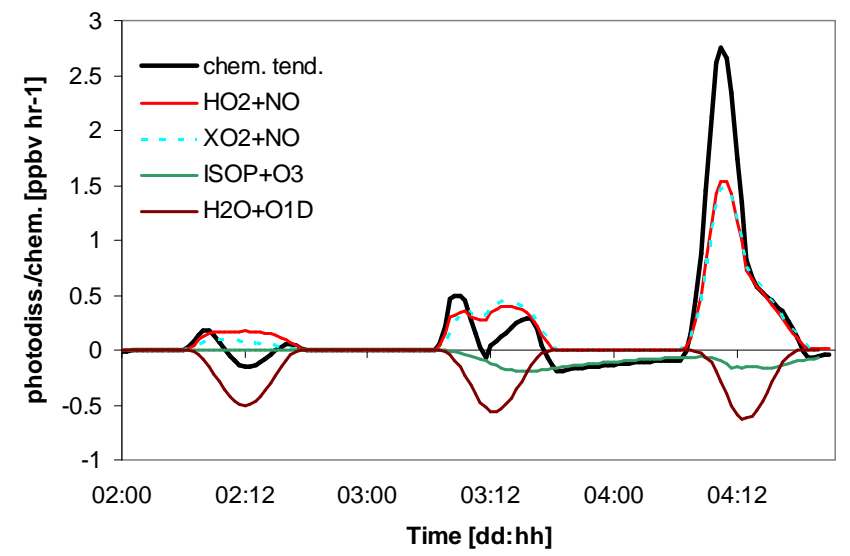

Fig. 10. Simulated $\mathrm{O}_{3}$ surface layer chemical tendency and the different production and destruction terms (ppbv hr ${ }^{-1}$ ) from 2-4 October. Only the reactions with a tendency $>5 \%$ of the difference between the minimum and maximum net chemical tendency are shown. $\mathrm{XO}_{2}$ represents the alkylperoxy radicals.

Interpretation of the process tendencies provides indications about the role of the various processes as shown in Fig. 9 for the surface layer for 2-4 October. For 2nd October during which air masses are transported over the Atlantic Ocean the main processes that control surface layer $\mathrm{O}_{3}$ mixing ratios are oceanic dry deposition, with a rather constant removal rate of $\sim 0.3 \mathrm{ppbv} \mathrm{hr}^{-1}$, largely compensated by downward turbulent transport and a relative small chemical production in the morning. Over land the (surface layer) dry deposition tendency is negligible since the role of dry deposition is considered in the canopy layers. Over the canopy the net tendency is controlled by relatively large chemical production terms in the morning, with a maximum $\mathrm{O}_{3}$ production of $3 \mathrm{ppbv} \mathrm{hr}^{-1}$ in the early hours of 4 th October. This production is, however, partly compensated by turbulent transport resulting in a net increase of $\sim 2 \mathrm{ppbv} \mathrm{hr}^{-1}$ in the early morning following the nocturnal depletion through transport into the canopy and the subsequent small dry deposition and chemical destruction. To put the net and chemical tendencies into perspective, the daytime turbulent tendencies reflect the net change in surface layer $\mathrm{O}_{3}$ due to a large flux from aloft and a flux into the canopy where dry deposition provides an efficient sink with simulated maximum destruction rates of $\sim 20 \mathrm{ppbv} \mathrm{hr}^{-1}$.

To interpret the nocturnal and morning chemical destruction and production tendencies we show in Fig. 10 the net chemical tendency as well as the main reactions that contribute to the net tendency in the surface layer. It appears that the simulated nocturnal $\mathrm{O}_{3}$ depletion can be attributed to isoprene oxidation whereas the relatively strong production of $\mathrm{O}_{3}$ in the morning is mostly due to the NO- $\mathrm{HO}_{2}$ and $\mathrm{NO}-\mathrm{XO}_{2}\left(\mathrm{XO}_{2}\right.$ represents the alkylperoxy radicals in the SCM's chemistry scheme) reactions. This reflects especially the release of $\mathrm{NO}_{\mathrm{x}}$, which has accumulated within the

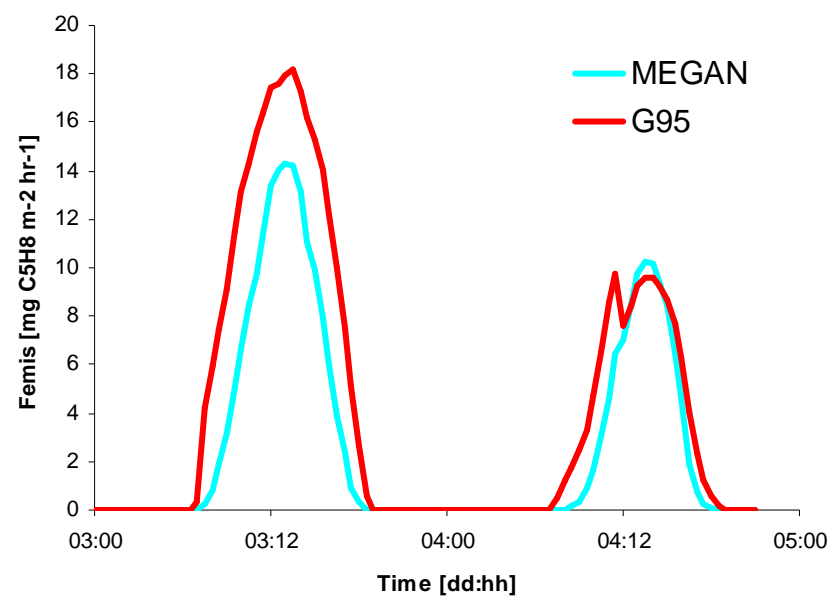

Fig. 11. Comparison of isoprene emission flux $\left(\mathrm{mg} \mathrm{C}_{5} \mathrm{H}_{8} \mathrm{~m}^{-2} \mathrm{~h}^{-1}\right)$ simulated with the Guenther et al. (1995) (G95) and the MEGAN algorithm for 3-4 October.

canopy during the night, into the surface layer and the rapidly growing boundary layer. These features of $\mathrm{O}_{3}$ chemistry and exchanges emphasize the importance of nocturnal and early morning atmosphere-biosphere exchange processes to interpret and quantify daytime tropical atmospheric chemistry, in line with the previous discussion about methanol and acetone exchanges. The reasonable agreement between observed and simulated $\mathrm{NO}$ and $\mathrm{O}_{3}$ mixing ratios, continental photolysis rates in the $\mathrm{BL}$ and soil-biogenic $\mathrm{NO}_{\mathrm{x}}$ exchanges shows that the model simulates key features of $\mathrm{NO}_{\mathrm{x}}$ and $\mathrm{O}_{3}$ atmospherebiosphere exchanges and evolution of and transport within the BL over the Guyana forests during GABRIEL.

\subsection{Volatile organic compounds: isoprene and oxidation products}

Isoprene emitted by tropical forests provides a large source of reactive hydrocarbon precursor for tropical forest boundary layer chemistry. The subsequent oxidation of $\mathrm{C}_{5} \mathrm{H}_{8}$ by $\mathrm{OH}, \mathrm{O}_{3}$ and $\mathrm{NO}_{3}$ yields relatively short-lived carbonyls such as MVK, MACR, and further breakdown subsequently leads to formaldehyde (HCHO) and CO. Isoprene is also known to act as a potentially significant source of secondary organic aerosols (SOA) (e.g., Claeys et al., 2004; Kroll et al., 2006). A common problem of large-scale atmospheric chemistry models, as well as the SCM, is that simulations based on the commonly applied Guenther et al. (1995) emission algorithm generally result in a large overestimation of the $\mathrm{C}_{5} \mathrm{H}_{8}$ mixing ratios in the boundary layer over tropical forest (e.g., Houweling et al., 1998). Simulated maximum mixing ratios can exceed 10-15 ppbv compared to observations usually below $\sim 5$ ppbv. Consequently, a commonly applied approach in global atmospheric chemistry studies is to use a substantially smaller flux, ranging from 220 to $350 \mathrm{TgC} \mathrm{yr}^{-1}$ (Brasseur et al., 1998; von Kuhlmann et al., 


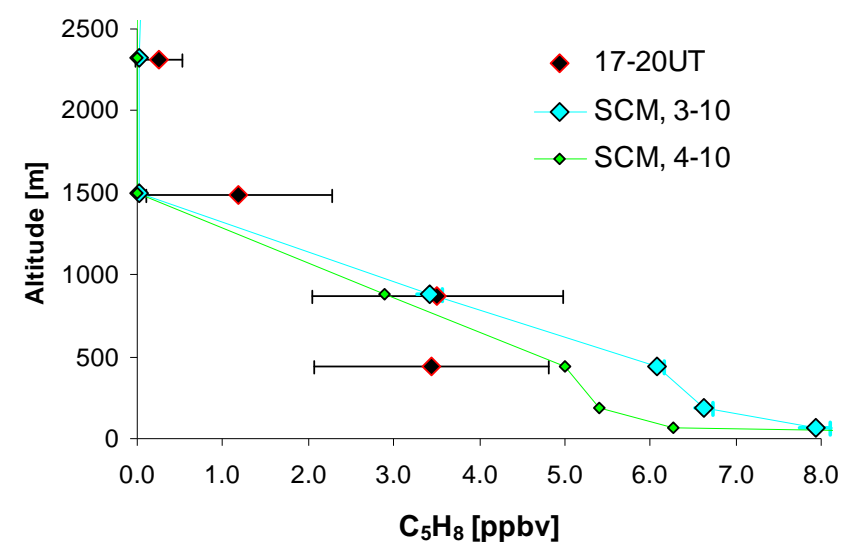

Fig. 12. Simulated and observed $\mathrm{C}_{5} \mathrm{H}_{8}$ mixing ratio (ppbv) profiles over land, 17:00-20:00 UT for 3-4 October also including the simulated mixing ratios below the observational domain.

2004), compared to $500 \mathrm{TgC}^{-1}$ according to Guenther et al. (1995). It appears that explaining the overestimation of tropical $\mathrm{C}_{5} \mathrm{H}_{8}$ concentrations in models requires an approach integrating chemistry, micrometeorology and vertical transport all being partly responsible. For example, von Kuhlmann et al. (2004) concluded that their model simulates too steep vertical $\mathrm{C}_{5} \mathrm{H}_{8}$ gradients compared to observations collected during the CLAIRE-1998 campaign (Warneke et al., 2001) over the Suriname tropical forest suggesting an underestimation of vertical transport.

We use the observations collected during GABRIEL to help constrain the representation of various processes in our SCM. Figure 11 shows a comparison of the simulated $\mathrm{C}_{5} \mathrm{H}_{8}$ emission fluxes using an implementation of the Guenther et al. (1995) emission algorithm (hereafter G95) and the more recent MEGAN (Model of Emissions of Gases and Aerosols from Nature) (Guenther et al., 2006) algorithm for 3-4 October. The maximum MEGAN emission fluxes of about $14 \mathrm{mg} \mathrm{C}_{5} \mathrm{H}_{8} \mathrm{~m}^{-2} \mathrm{~h}^{-1}$ are smaller compared to the $\mathrm{G} 95$ fluxes for 3rd October whereas for 4th October, with lower net radiation compared to the previous day, emission fluxes by both algorithms are comparable. Note that the algorithms differ in that the MEGAN basic emission factor (emission fluxes for a reference optimum temperature and radiation conditions) is a canopy-scale emission factor compared to the leaf-level emission factor of G95. However, since we explicitly calculate the role of canopy processes in our multi-layer exchanges model we have recalculated (using the foliar density in $\mathrm{g} \mathrm{m}^{-2}$ ) the MEGAN emission factor to a leaf-level emission factor. The latter is used to calculate the emission flux in each canopy layer and from that the effective release of $\mathrm{C}_{5} \mathrm{H}_{8}$ from the canopy to the atmosphere. The simulated canopy-top $\mathrm{C}_{5} \mathrm{H}_{8}$ flux is generally $90 \%$ of the emission flux suggesting a relatively small decrease in the release of $\mathrm{C}_{5} \mathrm{H}_{8}$ due to within-canopy chemical transformations and removal through soil uptake (Cleveland and Yavitt, 1997).

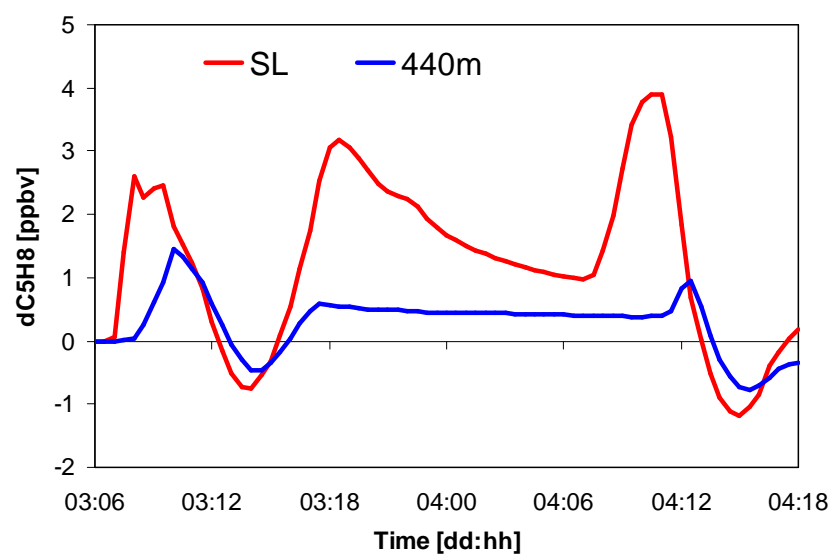

Fig. 13. Difference in $\mathrm{C}_{5} \mathrm{H}_{8}$ mixing ratios (ppbv) in the surface layer (SL) and the middle of the BL $(\sim 440 \mathrm{~m})$ for the same integrated emission fluxes simulated with the G95 and MEGAN implementation in the SCM.

It can been inferred from Fig. 11 that the MEGAN simulated isoprene fluxes show a significant delay in the onset of the emissions after sunrise and they decrease more rapidly in the late afternoon compared to G95. The simulated MEGAN maximum and 09:00-17:00 UT average flux, of $\sim 14$ and $10 \mathrm{mg}$ isoprene $\mathrm{m}^{-2} \mathrm{~h}^{-1}$, respectively, is a factor $\sim 2$ larger compared to the surface emission flux derived from observations of $\sim 7.3 \mathrm{mg} \mathrm{C}_{5} \mathrm{H}_{8} \mathrm{~m}^{-2} \mathrm{~h}^{-1}$. This flux has been inferred from the observed changes in the concentration of $\mathrm{C}_{5} \mathrm{H}_{8}$ and main oxidation products including MVK, MACR and the BL height (Eerdekens et al., 2008). This factor 2 difference between the MEGAN and inferred emission fluxes is within the stated uncertainty in MEGAN isoprene emission estimates of $50 \%$.

For the evaluation of the BL mixing ratios of $\mathrm{C}_{5} \mathrm{H}_{8}$ we applied an isoprene emission flux reduced by a factor 2 (hereafter referred to as $\mathrm{F}_{\mathrm{emisop}=0.5}$ ). Figure 12 shows a comparison of the simulated and observed $\mathrm{C}_{5} \mathrm{H}_{8}$ mixing ratios up to an altitude of $2500 \mathrm{~m}$ for the $\mathrm{F}_{\text {emisop}}=0.5$ simulation for 3-4 October, 17:00-20:00 UT. The comparison indicates reasonable agreement between the simulated and observed maximum mixing ratios in the middle of the BL $(\sim 400-500 \mathrm{~m})$ with observed mixing ratios $\sim 3 \mathrm{ppbv}$. The simulated relative decrease in mixing ratio for 4 th October compared to 3 rd October resembles the decrease in simulated emission fluxes between the two days, shown in Fig. 11. The comparison also indicates, consistent with the findings by von Kuhlmann et al. (2004), that the model simulates a larger decrease in the mixing ratios with altitude compared to the observed profiles (above the minimum flight altitude of $\sim 300 \mathrm{~m}$ ) suggesting that the model underestimates the (turbulent) upward transport. Moreover, the observation of about $0.5 \mathrm{ppbv}$ isoprene above the BL compared to a simulated mixing ratio close to zero suggests that convective transport to higher altitudes is underestimated. 


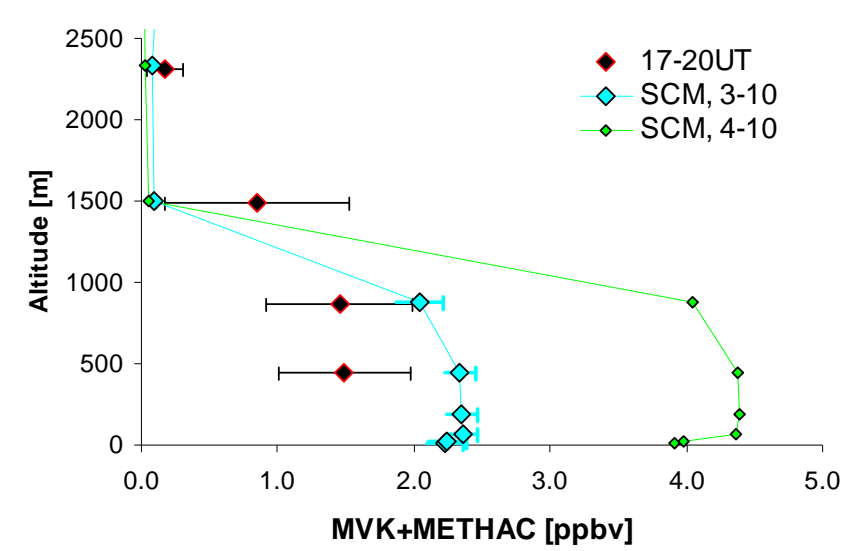

Fig. 14. Simulated and observed MVK+MACR mixing ratio (ppbv) profiles over land, 17:00-20:00 UT for 3-4 October also including the simulated mixing ratios below the observational domain.

Interpretation of the simulated mixing ratios for the two emission algorithms indicates that, in addition to the decrease in the emission flux by a factor 2 , also the distinctly different diurnal cycle in $\mathrm{C}_{5} \mathrm{H}_{8}$ emission fluxes is relevant to the BL mixing ratios. To isolate the impact of different diurnal cycles between the G95 and MEGAN emission fluxes on $\mathrm{BL}$ mixing ratios of $\mathrm{C}_{5} \mathrm{H}_{8}$ we have selected the emission factor such that the 3-4 October integrated emission flux using the G95 algorithm resembles the integrated flux of the $\mathrm{F}_{\text {emisop }=0.5}$ MEGAN emission flux simulation. Figure 13 shows the difference between the $\mathrm{C}_{5} \mathrm{H}_{8}$ mixing ratios in the surface layer (SL) and the middle of the BL ( $440 \mathrm{~m})$ simulated with the G95 and MEGAN emission algorithms (calculated as G95-MEGAN), showing maximum differences of about 2 ppbv and $1 \mathrm{ppbv}$ (relative to $\sim 5 \mathrm{ppbv}$ and $\sim 3 \mathrm{ppbv}$ ) in the surface layer and middle of the BL, respectively. These differences, with a pronounced impact on long-term average mixing ratios (often used for the evaluation of large-scale chemistry models) occur in the early morning when suppressed turbulent mixing conditions result in a high sensitivity to the timing of the onset of emissions. These findings demonstrate that evaluation of large-scale chemistry models by comparison of surface or BL mixing ratios requires a careful analysis and consistent representation of temporal variability in surface sources and sinks as well as turbulent transport.

\subsection{Oxidation products}

\subsubsection{Methyl vinyl ketone, methacrolein and formalhyde}

Evaluation of the isoprene chemistry over the Guyana forest involves comparison of the simulated and observed oxidation products, methyl vinyl ketone (MVK), methacroleine (MACR) and formaldehyde (HCHO). Figure 14 shows a comparison of the vertical profile of the observed summed MVK and MACR mixing ratios over land for 17:00-

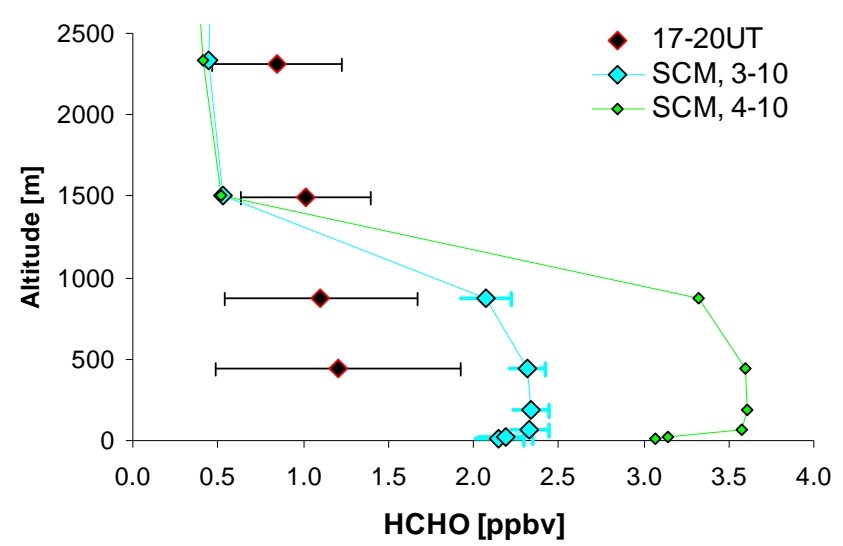

Fig. 15. Simulated and observed $\mathrm{HCHO}$ mixing ratio (ppbv) profiles over land, 17:00-20:00 UT for 3-4 October also including the simulated mixing ratios below the observational domain.

20:00 UT and the simulated vertical profile for 3 and 4 Octo-

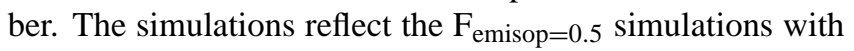
MEGAN. We obtain good agreement between the observed and simulated mixing ratios for 3rd October although the model simulates a further increase in MVK+MACR mixing ratios with the air column being transported further inland. This increase reflects the combined effect of chemical production and loss, dilution through mixing and surface deposition, as indicated by the simulated mixing ratio gradient in the surface layer and canopy. Surface deposition is calculated using the aforementioned approach by Wesely (1989) using estimated reactivities and Henry's law coefficients similar to those used by von Kuhlmann et al. (2004) in a study of the sensitivity of the global isoprene budget to processes including deposition of oxidation products. This results in simulated MVK and MACR dry deposition velocities $\left(V_{d}\right)$ which are slightly smaller compared than those of $\mathrm{O}_{3}$ and $\mathrm{SO}_{2}$ (maximum daytime $V_{d} \sim 1 \mathrm{~cm} \mathrm{~s}^{-1}$ and nocturnal $V_{d}$ $\sim 0.1 \mathrm{~cm} \mathrm{~s}^{-1}$ ). However, it should be noted that the nighttime destruction by surface deposition does not result in a substantial nocturnal decrease in MVK+MACR mixing ratios. On the contrary, especially in the residual layer overlaying the inversion layer the model simulates a further increase in MVK+MACR mixing ratios associated with nocturnal isoprene destruction through its reaction with $\mathrm{O}_{3}$. This results in maximum residual layer MVK+MACR mixing ratios up to $2 \mathrm{ppbv}$, which are entrained into the developing BL the next day.

Unfortunately the early morning observations in the residual layer during GABRIEL are too few to evaluate this feature of nocturnal accumulation of isoprene oxidation products in the residual layer. Observations by Warneke et al. (2001), which were collected over Suriname in the LBA-CLAIRE 1998 campaign, show residual layer concentrations of MVK+MACR of the order of 400 pptv, substantially smaller compared to the simulated residual layer 


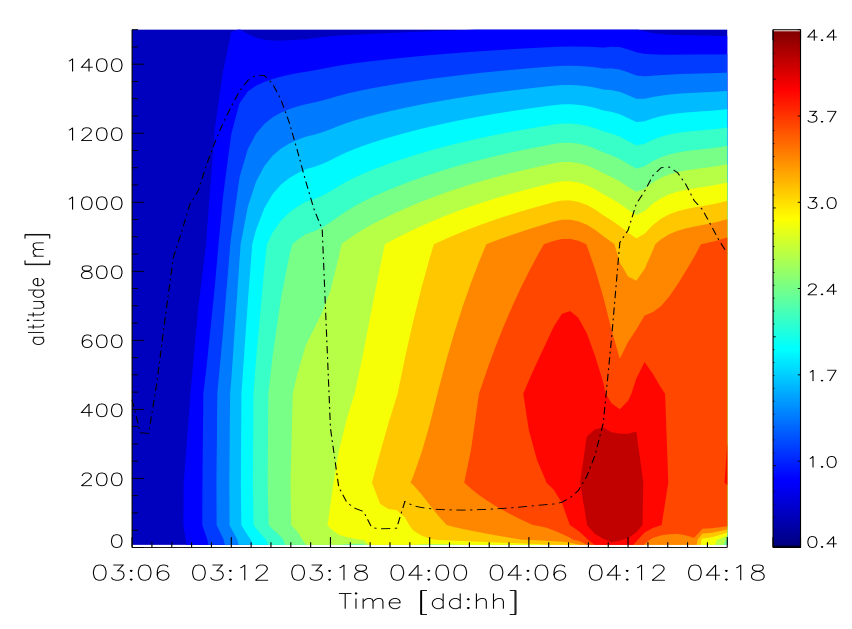

Fig. 16. Simulated HCHO mixing ratios (ppbv) over land on 3-4 October, up to $1500 \mathrm{~m}$. The black dashed line denotes the diagnostic BL height.

mixing ratios. However, these observations were collected in March and April 2001 with the prevailing wind direction being northeast, in contrast to GABRIEL with the main wind direction being east to southeast, the latter resulting in a substantially longer residence time of the sampled air masses over land than during LBA-CLAIRE1998. Surface observations of VOCs collected during LBA-CLAIRE1998 at a site about $1000 \mathrm{~km}$ further downwind and in-land at the site of Balbina, Brazil (Kesselmeier et al., 2000), show similarly small MVK+MACR mixing ratios. We have conducted an additional SCM simulation in which we have applied a substantially larger surface removal efficiency, assuming zero resistance against uptake by the dry and wet vegetation. Unsurprisingly, this simulation shows a very strong depletion of surface and canopy MVK+MACR mixing ratios but does not result in a substantial decrease in the residual layer mixing ratios simply because nocturnal turbulent transport is completely suppressed in the SCM. This is a feature of all atmospheric chemistry models, while observations show that nocturnal intermittent transport events actually occur regularly. For example, observations by Fitzjarrald and Moore (1990) and Acevedo et al. (2006) provide evidence of the important role of nocturnal intermittent turbulent transport in tropical forest exchanges of energy, moisture and $\mathrm{CO}_{2}$. Fitzjarrald and Moore (1990) postulated a mechanism to explain this intermittent exchange regime by the breakdown of the nighttime inversion through enhanced shear associated with the presence of a nocturnal jet. Such local-scale processes are not yet resolved in models, including our SCM, and we recommend further analysis that would ultimately result in the development of parameterizations of enhanced nocturnal mixing in atmospheric chemistry models.
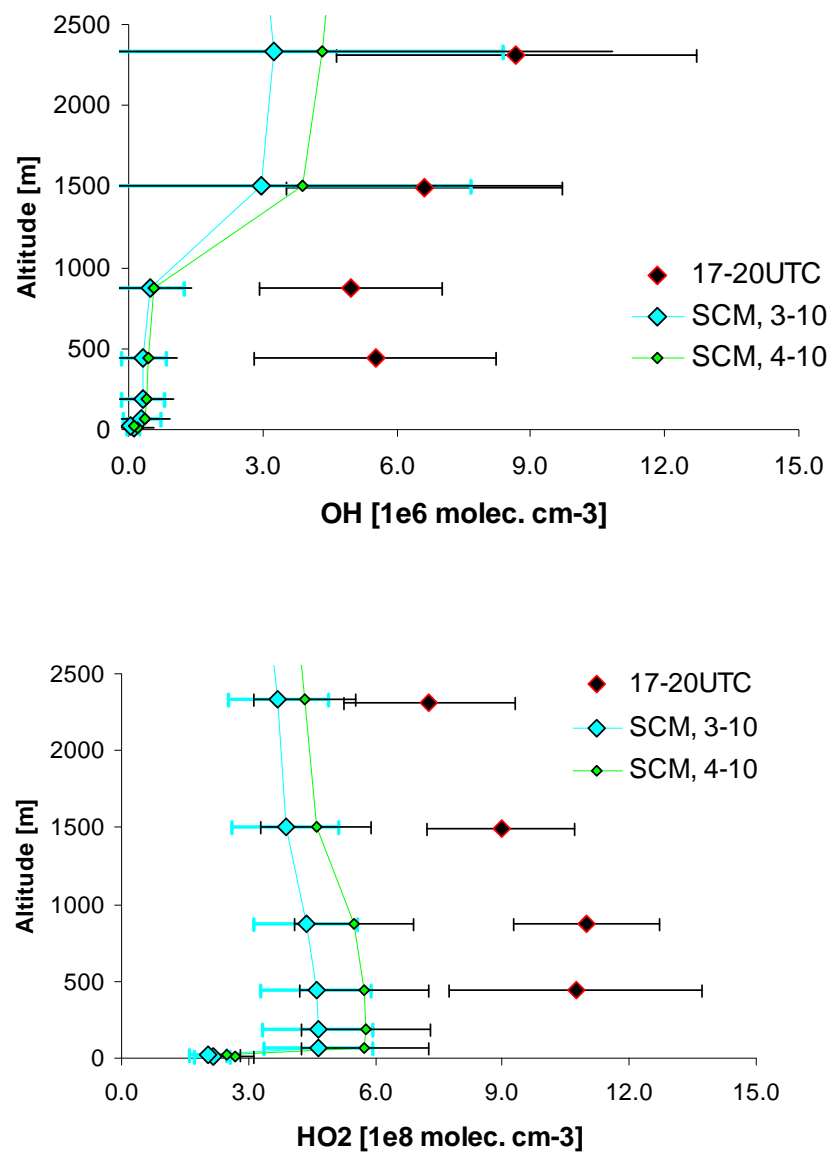

Fig. 17. Simulated and observed $\mathrm{OH}$ (a) and $\mathrm{HO}_{2}$ (b) concentration $\left(10^{6}\right.$ and $10^{8}$ molecules $\mathrm{cm}^{-3}$, respectively) profiles over land, 17:00-20:00 UT for 3-4 October also including concentrations below $440 \mathrm{~m}$.

For another important isoprene oxidation product, $\mathrm{HCHO}$, the simulations based on the uncorrected MEGAN $\mathrm{C}_{5} \mathrm{H}_{8}$ emission flux yields BL mixing ratios in excess of $6 \mathrm{ppbv}$ for 4th October, which is significantly higher compared to the observed $\mathrm{HCHO}$ mixing ratio. Figure 15 shows a comparison of observed and simulated $\mathrm{HCHO}$ mixing ratio profiles for 3-4 October, 17:00-20:00 UT, applying the reduced MEGAN emission flux simulations. It can be clearly seen that the model overestimates HCHO mixing ratios in the lower $1000 \mathrm{~m}$ of the BL, whereas it underestimates the $\mathrm{HCHO}$ mixing ratios at the top of the BL and in the free troposphere. The underestimation above $1 \mathrm{~km}$ height is consistent with the misrepresentation of the $\mathrm{C}_{5} \mathrm{H}_{8}$ mixing ratio profile discussed above. It is likely related to the underestimation of convective mixing and isoprene and $\mathrm{HCHO}$ oxidation by $\mathrm{OH}$. Furthermore, it is conceivable that the CBM4 higher hydrocarbon chemistry mechanism applied in our SCM may misrepresent isoprene chemistry for low- $\mathrm{NO}_{\mathrm{x}}$ conditions. The yield of formaldehyde from the lumping of hydrocarbons and reaction products may be overestimated, bearing in 
mind that CBM4 has been developed and tested for higher$\mathrm{NO}_{\mathrm{x}}$ conditions compared to those encountered during the GABRIEL campaign. The removal of $\mathrm{HCHO}$ by wet deposition is considered in the SCM although this seems to be only a small sink compared to that due to photochemical loss and dry deposition. This is consistent with the actual meteorological conditions encountered during GABRIEL with local precipitation events in deep convection approximately once every three days. For a more elaborate discussion on the role of dry deposition in explaining some of the discrepancies between observed and simulated $\mathrm{HCHO}$ mixing ratios in the BL we refer to Stickler et al. (2007).

To understand the increase in mixing ratios in the lower BL between 3 and 4 October, similar to that shown for MVK+MACR, we show in Fig. 16 the simulated HCHO mixing ratios for this period up to $1500 \mathrm{~m}$. The diagnostic BL height is also shown. It can be inferred from Fig. 16 that the model simulates a daytime increase in the BL mixing ratios reflecting daytime chemical production, turbulent (and convective) transport and dry deposition. However, it can also be inferred that there is a continuous nocturnal source of $\mathrm{HCHO}$ through the oxidation of isoprene by ozone, which results in the accumulation of $\mathrm{HCHO}$ in the residual layer, providing an additional source of $\mathrm{HCHO}$ in the early morning through the entrainment of these air masses into the growing BL. As mentioned earlier, this mechanism indicated by our SCM simulations cannot be directly tested by comparing with observations in the residual layer.

\subsection{Hydroxyl and peroxy radicals}

The preceding model evaluation of the various species observed during GABRIEL provides insight in atmospherebiosphere exchanges and the control of reactive species over the Guyana coastal region and tropical forest. To evaluate the modeled radical chemistry we show in Fig. 17a comparison of simulated and observed $\mathrm{OH}$ and $\mathrm{HO}_{2}$ concentrations over land for 3-4 October for 14:00-17:00 LT. Clearly, despite the reasonable agreement between observed and simulated precursor concentrations involved in radical chemistry, the SCM significantly underestimates $\mathrm{OH}$ and $\mathrm{HO}_{2}$ concentrations, in particular within the BL. The model partitioning of the $\mathrm{OH}$ reaction tendency indicates that the simulated main $\mathrm{OH}$ source is ozone photolysis followed by the production from $\mathrm{HO}_{2}$ reacting with $\mathrm{NO}$ and $\mathrm{O}_{3}$. However, the previously presented agreement between observed and simulated $\mathrm{H}_{2} \mathrm{O}$, $\mathrm{O}_{3}$ and $\mathrm{NO}$ mixing ratios as well as photolysis rates in the $\mathrm{BL}$ suggests that this misrepresentation of $\mathrm{OH}$ in the $\mathrm{BL}$ can not be explained in terms of these two predominant sources of $\mathrm{OH}$. This points to either, a misrepresentation of the $\mathrm{OH}$ sink, which, according to our simulation, is dominated by the $\mathrm{C}_{5} \mathrm{H}_{8}-\mathrm{OH}$ reaction, or a missing source of $\mathrm{OH}$. The evaluation of $\mathrm{C}_{5} \mathrm{H}_{8}$ mixing ratio profiles has indicated that, despite the fact that the simulated mixing ratio in the middle of the BL agrees well with observations, the simulated vertical gradient is overestimated with too high mixing ratios in the lower $\mathrm{BL}$ and an underestimation of $\mathrm{C}_{5} \mathrm{H}_{8}$ higher up in the BL. However, the comparison reveals a bias between the observed and simulated $\mathrm{OH}$ concentrations that does not change much with height suggesting that misrepresentation of $\mathrm{C}_{5} \mathrm{H}_{8}$, in particular of the vertical profile, is not the only explanation of the strong underestimation of radical concentrations in the BL. This is confirmed by a simulation with a much higher vertical resolution, discussed in the next section, resulting in more efficient upward transport and, consequently, smaller vertical BL gradients in isoprene but which does not result in a substantial increase in $\mathrm{OH}$ and $\mathrm{HO}_{2}$ concentrations.

We have conducted a number of sensitivity analyses including one with enhanced ozone mixing ratios above the $\mathrm{BL}$, in better agreement with observations, and one in which we applied higher photolysis rates also to consider the impact of the SCM's misrepresentation of clouds. Those analyses showed indeed an increase in $\mathrm{OH}$ and $\mathrm{HO}_{2}$ concentrations and improved agreement between the observation and the SCM but mostly restricted to the lower free troposphere. One particular sensitivity analysis aimed to assess the role of potential missing $\mathrm{OH}$ formation through terpene ozonolysis. This was also motivated by the role of these reactions in producing $\mathrm{OH}$ inside the canopy for daytime as well as nocturnal conditions (e.g., Faloona et al., 2001) and the fact that visible observations from the aircraft clearly indicated the presence of a haze layer. Since biomass burning sources were not important for most of the campaign this haze likely results from the oxidation of biogenic precursor emissions (such as terpenes) in the formation of secondary organic aerosols (SOA). Furthermore monoterpenes were measured from the aircraft at mixing ratios of circa 10$20 \%$ of isoprene (Williams et al. 2007). Karl et al. (2007) stated that, based on an analysis combining a photochemical box model and a mixed layer budget approach to study VOC exchanges over Amazonia, the large discrepancy between the simulated and inferred $\mathrm{OH}$, could be explained by ozonolysis of sesquiterpenes with a mixing ratio of $\sim 1 \%$ of that of isoprene. Here we complement this analysis through explicit numerical integration to assess in particular the interaction between vertical turbulent (and convective) transport and chemical transformations. We extended the CBM4 chemistry mechanism of the SCM to consider $\mathrm{OH}$ oxidation and ozonolysis of the monoterpenes $\alpha$-pinene and $\beta$-pinene (Ganzeveld et al., 2006b) and terpinolene. Note that this extension does not consider detailed reactions involving the products and should therefore be interpreted as an indication of the first-order potential impact of these reactions on $\mathrm{OH}$ in the BL. Selection of the monoterpene terpinolene was based on the chemical timescale of its reaction with $\mathrm{OH}$ and $\mathrm{O}_{3}$ and the $\mathrm{OH}$ yield of the ozonolysis reaction rather than on knowledge about speciated VOC emissions from tropical forests (Andreae et al., 2002; Kesselmeier et al., 2002; Williams et al. 2007; Karl et al., 2007). 
In addition to the efficiency of $\mathrm{OH}$ production the timescales of the reactions of terpenes with $\mathrm{O}_{3}$ are crucial in explaining 1) if more $\mathrm{OH}$ is produced than consumed and 2) if the vertical distribution of $\mathrm{OH}$ production by terpene ozonolysis within the BL is dependent on the relative ratio of the chemical and the turbulent timescale. With a typical vertical updraft velocity of the order of $1-2 \mathrm{~m} \mathrm{~s}^{-1}$ (e.g., Karl et al., 2007) and a BL height up to $1500 \mathrm{~m}$ the turbulent mixing timescale is about 15-30 min. For example, the sesquiterpene humulene reacts relatively slowly with $\mathrm{OH}$ compared to the reaction with $\mathrm{O}_{3}$ (with an $\mathrm{OH}$ yield of 0.22 ), thus providing a potential source of $\mathrm{OH}$; however, the latter reaction has a timescale of the order of 2 min (for an $\mathrm{O}_{3}$ mixing ratio of $\sim 29 \mathrm{ppbv}$ ) (Atkinson and Arey, 2003). This suggests that $\mathrm{OH}$ production from the ozonolysis of humulene is largely restricted to the canopy and surface layer (lower $50-100 \mathrm{~m}$ ). The same applies to the sesquiterpene $\beta$-caryophyllene, which according to Karl et al. (2007) could possibly explain the discrepancy between the model simulated- and inferred $\mathrm{OH}$ concentrations. However, it seems that they did not consider the limited altitude range of this potential $\mathrm{OH}$ source. In contrast, the chemical timescale of the $\mathrm{O}_{3}$-terpinolene reaction, with an $\mathrm{OH}$ yield $>0.74( \pm 0.10)$ (Atkinson and Arey, 2003), is of the order of 13 minutes. However, simulations with a range of terpinolene emission fluxes indicate that, to provide a substantial source of $\mathrm{OH}$ throughout the BL, an emission flux one order of magnitude larger compared to the simulated monoterpene emission fluxes is required. Actually such a flux of reactive terpenes as a source of $\mathrm{OH}$ through ozonolysis would be comparable to the isoprene emission flux, which seems unrealistic also from the point of view that further reactions would lead to higher concentrations of reactions products including formaldehyde and organic peroxides than has been observed. Therefore, an explanation for the identified large discrepancy between observed and simulated $\mathrm{OH}$ concentrations has been pursued in the isoprene oxidation mechanism, as discussed in more detail by Lelieveld et al. (2008) and Butler et al. (2008). Here we address the uncertainty in the $\mathrm{HO}_{\mathrm{x}}$ precursor concentrations associated with the demonstrated discrepancy between the simulated and observed $\mathrm{HO}_{\mathrm{x}}$ levels. This has been assessed through the introduction of a first-order estimate of the extra $\mathrm{OH}$ source involved in the isoprene oxidation mechanism. Since the lumping of hydrocarbon compounds in the CBM4 scheme of our model is different from that in the MIM chemistry scheme we have considered the recycling of $\mathrm{OH}$ associated with isoprene oxidation (Lelieveld et al., 2008; Butler et al., 2008) using the CBM4 reaction between $\mathrm{HO}_{2}$ and alkylperoxy radicals $\left(\mathrm{XO}_{2}\right)$ mainly formed in the oxidation of organic compounds (see also Roelofs and Lelieveld, 2000). Scaling the amount of $\mathrm{XO}_{2}$ produced from the oxidation of isoprene and isoprene products (ISOPRD) with the total production of $\mathrm{XO}_{2}$ and taking an additional yield (on top of a yield of 0.4 in the CBM4 implementation) of $4.5 \mathrm{OH}$ radicals for the $\mathrm{XO}_{2}+\mathrm{HO}_{2}$ reaction we simulate maximum $\mathrm{BL} \mathrm{OH}$ and $\mathrm{HO}_{2}$ concentrations of about $\sim 5.5 \times 10^{6}$ molecules $\mathrm{OH} \mathrm{cm}^{-3}$ and $13 \times 10^{8}$ molecules $\mathrm{HO}_{2} \mathrm{~cm}^{-3}$, respectively, for 17:00-20:00 UT, in reasonable agreement with the observations. This substantial increase in $\mathrm{HO}_{\mathrm{x}}$ induces only a small relative increase ( $\sim 10 \%$, relative to low $\mathrm{HO}_{\mathrm{x}}$ simulation) in the BL ozone mixing ratios. There is a decrease in isoprene mixing ratios $>80 \%$, resulting in simulated $\mathrm{BL}$ average mixing ratios of about $1 \mathrm{ppbv}$, being substantially lower than observed and consistent with the findings of Butler et al. (2008). The simulated enhanced $\mathrm{HO}_{\mathrm{x}}$ concentrations also result in an about $80 \%$ decrease in $\mathrm{NO}_{\mathrm{x}}$ mixing ratios (due to a simulated enhanced production of $\mathrm{HNO}_{3}$ and other reservoir species). These simulated decreases in both the isoprene and $\mathrm{NO}_{\mathrm{x}}$ mixing ratios due to the enhanced $\mathrm{HO}_{\mathrm{x}}$ concentrations would require a substantial increase ( $>$ factor 2 ) in both the isoprene and NO emission fluxes to reconcile the simulated and observed isoprene and NO mixing ratio profiles as shown in Fig. 12 and 5b, respectively. One possible explanation to reconcile the observed and simulated isoprene mixing ratios for the high $\mathrm{HO}_{\mathrm{x}}$ regime could be a reduced efficiency of the isoprene-OH reaction associated with non-homogenous mixing conditions (the so-called intensity of segregation) proposed by Butler et al. (2008). Finally, the enhanced $\mathrm{HO}_{\mathrm{x}}$ concentrations result in decreases in MVK-METHAC mixing ratios of $\sim 50 \%$, reflecting the combined effect of the enhanced production from isoprene oxidation and the substantial decrease in isoprene mixing ratios. Changes in the MVK-METHAC mixing ratio profile (Fig. 14) are comparable to the changes induced by a different representation of turbulent tracer transport as discussed in the next section.

\section{Discussion of turbulent transport}

\subsection{Breakdown of inversion}

In Sects. 3 and 4 it has been demonstrated that through the adjustment of soil moisture in the SCM the simulated BL micrometeorology and atmospheric chemistry are brought into reasonable agreement with the observations. Figure $2 \mathrm{a}$ shows, for example, that the simulated median daytime Bowen ratio over land is in good agreement with observations in other tropical forest sites. However, a more careful analysis focusing especially on the early morning transition indicates that the SCM, and likely most chemistry and climate models which include similar representations of landatmosphere interactions, simulates a breakdown of the nocturnal inversion for 4th October about $3 \mathrm{~h}$ after sunrise which seems unrealistically long. Observations by da Rocha et al. (2004) suggest that positive Bowen ratios are already observed $1.5 \mathrm{~h}$ after sunrise. Figure 18 shows the net radiation $\left(\mathrm{R}_{g}\right)$, latent heat flux (LE) and Bowen ratio focusing on this early morning transition. It can be inferred that after sunrise around 06:00 LT the model simulates an increase in LE with 
increasing incoming radiation $\left(\mathrm{R}_{g}\right)$ until about 09:30 LT. The simulated early onset of evapotranspiration after sunrise results in an early morning decrease in skin temperature, further increasing surface layer stability and delaying the inversion breakdown. This (mis)representation of the transition in the turbulence regime is not only relevant for the evaluation of the $\mathrm{BL}$ micrometeorology but also for atmospheric chemistry.

Since many of the surface sources and sinks of reactive trace gases depend on radiation, the simulated too slow inversion breakdown results in the accumulation or depletion of species that are emitted or removed by chemical destruction or surface deposition, respectively. This in turn results in an unrealistic representation of the initial exchange flux between the inversion layer and the layers aloft after the inversion is destroyed, e.g., the morning bursts of $\mathrm{NO}_{\mathrm{x}}$ and VOCs that have accumulated during the night and early morning within the canopy. To assess the consequences of a possible misrepresentation of evapotranspiration during the breakdown of the inversion layer for atmospheric chemistry, we have conducted additional simulations in which we manipulated the SCM representation of evapotranspiration such that it increases less rapidly with an increase in radiation for low radiation intensities. The impact on the simulated latent heat flux as well as the Bowen ratio are also presented in Fig. 18, showing that the decrease in LE between about 06:00-09:00 LT compared to the default simulation results in a shortening of the inversion breakdown by about $1 \mathrm{~h}$. This results in a simulated maximum decrease in canopy-crown and surface layer $\mathrm{NO}_{\mathrm{x}}$ mixing ratios of about $20 \%$ one hour after sunrise and, later during the day, also results in maximum relative increases in $\mathrm{NO}_{\mathrm{x}}$ mixing ratios higher up in the deepening $\mathrm{BL}$ up to $10 \%$ compared to the default simulation. As a consequence $\mathrm{C}_{5} \mathrm{H}_{8}$ mixing ratios can differ by as much as $25 \%$. These results indicate the importance of a realistic and consistent model representation of energy, moisture and reactive trace gas exchanges, in particular during the early morning transition from the stable to the well mixed BL.

\subsection{Vertical resolution of the BL}

Because of the demonstrated misrepresentation of some of the vertical profiles of reactive air constituents, especially those of VOCs, we have conducted an analysis applying a much higher vertical resolution of 60 layers (L60) with about 13 layers representing the BL up to $1500 \mathrm{~m}$ altitude compared to the 5 layers in the default L19 resolution. The L60 resolution actually resembles that of the ECMWF data used to constrain the SCM simulations during the first day of the 3-day simulations. This analysis aims to investigate to what extent a higher vertical resolution in the BL results in an improved representation of surface and boundary layer turbulent transport and concentrations. Before showing the impact of using this substantially higher vertical resolution it is important to mention that the maximum simulated $\mathrm{BL}$

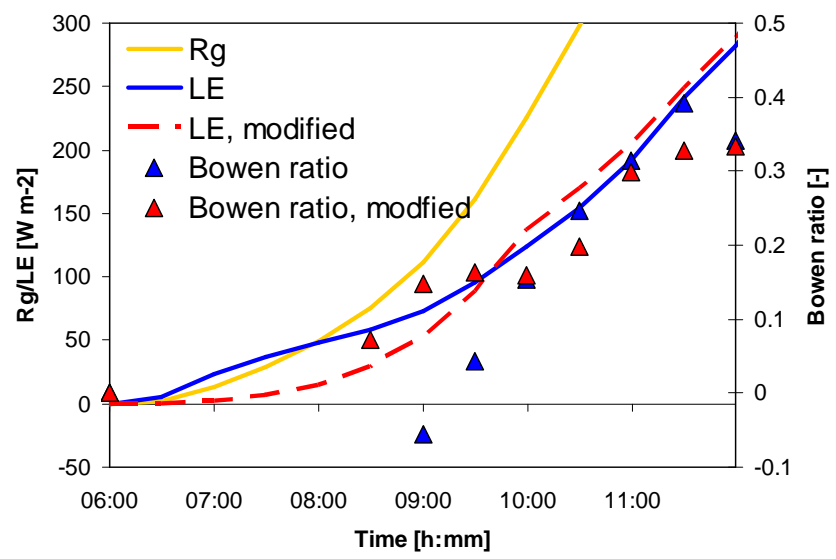

Fig. 18. Simulated surface net radiation ( $\mathrm{R}_{g}$, yellow), latent heat flux (LE, blue) and Bowen ratio (blue triangles) for the default run and LE (red dashed) and Bowen ratio (red triangles) for modified simulation to assess the duration of the early morning transition.

height for 3rd October is $1700 \mathrm{~m}$ compared to $1400 \mathrm{~m}$ in the L19 version, indicating more efficient upward transport in the simulation using the L60 resolution. The explanation of this more efficient transport including surface and BL turbulence as well as BL/FT exchanges still needs to be assessed. However, this more efficient upward transport is also reflected in the simulated vertical profiles of the $\mathrm{C}_{5} \mathrm{H}_{8}, \mathrm{MVK}+\mathrm{MACR}$ and HCHO mixing ratios shown in Fig. 19a, b and c, respectively. The $\mathrm{L} 60$ vertical profile of the $\mathrm{C}_{5} \mathrm{H}_{8}$ mixing ratio is steeper compared to that of the L19 simulations and in much better agreement with the observed vertical profile.

The more efficient upward transport in the L60 version is also clearly visible in the MVK+MACR and HCHO mixing ratio profiles, with a significantly improved representation of the MVK+MACR mixing ratio near the top of the BL and in the lower free troposphere. The L60 HCHO mixing ratio profile shows substantially lower BL mixing ratios compared to the L19 resolution but the mixing ratios are still overestimated with a distinct BL-free troposphere gradient that differs from the observations. In fact, the higher SCM resolution does not alleviate the model deficiency to simulate the enhanced convective mixing associated with the presence of shallow cumulus over the BL in the afternoon. Note that the significantly reduced mixing ratios in the lower BL do not only reflect the more efficient dilution in a deeper BL but also a more efficient removal of MVK+MACR and HCHO by dry deposition. Furthermore, interpreting the changes in the L19 and L60 VOC mixing ratio profiles between 3rd and 4th October indicates that the (mis)representation of the nocturnal mixing regime does not substantially change with the higher vertical resolution. The L60 simulations show, for example, a similar enhancement in the MVK+MACR mixing ratios comparing the 3-4 October surface layer mixing ratios for 14:00-17:00 LT (factor $\sim 1.5$ increase). However, it can 

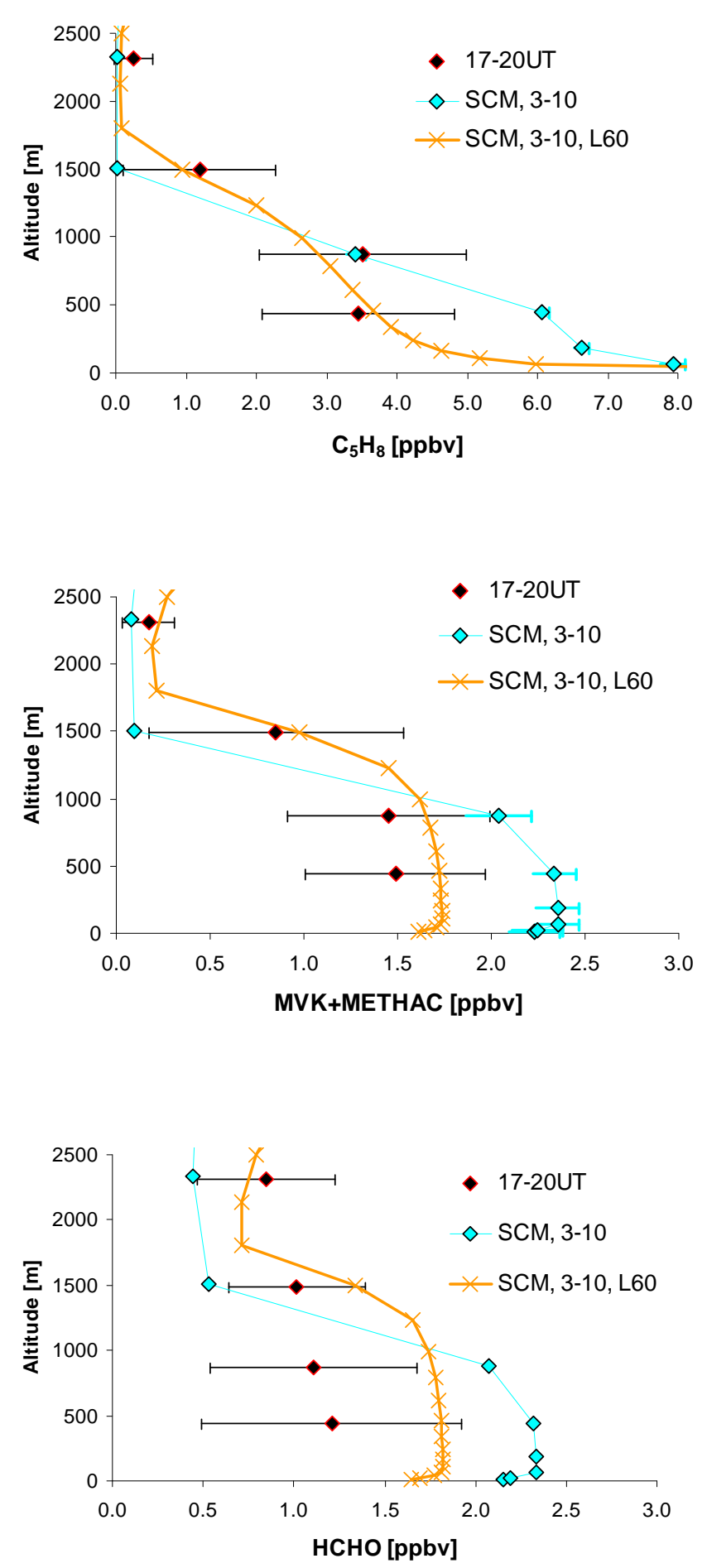

Fig. 19. Simulated and observed $\mathrm{C}_{5} \mathrm{H}_{8}$ (a) MVK+MACR (b) and HCHO (c) mixing ratio profiles over land, 17:00-20:00 UT for 3 October, showing the simulated mixing ratios for the default L19 and the L60 model resolution.

be concluded from these simulations that using an increased vertical resolution in the daytime convective BL compared to that commonly applied in large-scale atmospheric chemistry models seems to significantly improve the simulated turbulent exchanges and mixing ratio profiles of biogenic precursors and products over tropical forest.

\section{Conclusions}

Our study of the atmosphere-biosphere and boundary layer exchanges of $\mathrm{NO}_{\mathrm{x}}$, VOC's and $\mathrm{O}_{3}$ in the Guyanas during the GABRIEL campaign in October 2005 indicates that the observations generally reflect a pristine tropical forest low- $\mathrm{NO}_{\mathrm{x}}$ chemical regime. The consistency between observed and simulated BL micrometeorology and chemical exchanges, assuming a partly reduced availability of soil moisture, indicates that the conditions reflect a relatively dry though not a moisture-limited regime (consistent with the regular occurrence of precipitation events). Our evaluation also provides indications about the magnitude of the not-directly measured atmosphere-biosphere precursor fluxes and BL dynamics relevant to the interpretation of the airborne observations and other model analyses including those with the global chemistry-climate model ECHAM5/MESSy (Lelieveld et al., 2008; Butler et al., 2008). In addition, our evaluation reveals a number of issues which deserve increased priority in the interpretation of tropical forest atmosphere-biosphere exchanges and boundary layer evolution and turbulent transport. This includes bi-directional exchanges of oxygenated compounds and nocturnal and early morning trace gas exchanges. For example, we demonstrate that the currently applied algorithm to simulate global acetone and methanol biogenic exchanges appears to substantially overestimate the tropical forest source strengths.

We also emphasize the importance of understanding the temporal variability in mixing conditions including the nocturnal- and early morning transition for the interpretation of the daytime observations. The daytime isoprene chemistry is affected by the nocturnal removal and production processes in the inversion layer and residual layer aloft through the entrainment of air masses in which isoprene oxidation products such as MVK, MACR and $\mathrm{HCHO}$ accumulate during the night. It must still be assessed more quantitatively if this is a real or model feature recognizing that our SCM, as well as all other atmospheric chemistry and climate models, does not represent observed nocturnal transport phenomena such as intermittent exchange between the canopy, surface layer and atmosphere aloft. Consequently, future campaigns that aim at improving our understanding of tropical forest chemical exchanges should preferably also include measurements to facilitate the interpretation of nocturnal and early morning exchanges of reactive gases. We recognize that for reasons of safety, flying low over the rainforest in the dark is not possible for jet aircraft such as that used in this study. It is however hoped that because of the here demonstrated importance of this time period, we recommend that other platforms (e.g. Zeppelin combined with 
surface sites) be implemented in future studies. Moreover, such campaigns should include atmospheric chemistry and tracer measurements complemented with a selection of meteorological parameters prerequisite to characterize turbulent exchanges between the canopy and atmosphere including the residual layer.

Acknowledgements. We highly appreciate the contributions by the GABRIEL team and would like to thank in particular Christian Gurk ( $\mathrm{H}_{2} \mathrm{O}$ measurements), Uwe Parchatka (NO and $\mathrm{O}_{3}$ measurements), Corinne Schiller and Heiko Bozem (HCHO measurements). We also appreciate the input by Maarten Krol on some of modifications of the SCM's chemistry scheme and the constructive comments provided by two reviewers. The presented analysis is a contribution to GABRIEL campaign coordinated and funded by the Max-Planck-Institute for Chemistry.

Edited by: R. Cohen

\section{References}

Atkinson, R. and Arey, J.: Atmospheric degradation of Volatile Organic Compounds, Chem. Rev., 103, 4605-4638, 2003.

Acevedo, O. C., Moreas, O. L. L., Degrazia, G. A., and Medeiros, L.: Intermittency and the exchange of scalars in the nocturnal surface layer, Bound.-Lay. Meteorol., doi:10.1007/s10546-0059019-3, 2006.

Andreae, M. O., Chapuis, A., Cros, B., et al.: Biogeochemical cycling of carbon, water, energy, trace gases, and aerosols in Amazonia: The LBA-EUSTACH experiments, J. Geophys. Res., 107(D20), 8066, doi:10.1029/2001JD000524, 2002.

Brasseur, G. P., Hauglustaine, D. A., Walters, S., Rasch, P. J., Müller, J.-F., Granier, C., and Tie, X. X.: MOZART, a global chemical transport model for ozone and related chemical tracers 1. Model description, J. Geophys. Res., 103(D21), 28 26528 290, doi:10.1029/98JD02397, 1998.

Butler, T. M., Taraborrelli, D., Brühl, C., Fischer, H., Harder, H., Martinez, M., Williams, J., Lawrence, M. G., and Lelieveld, J.: Improved simulation of isoprene oxidation chemistry with the ECHAM5/MESSy chemistry-climate model: lessons from the GABRIEL airborne field campaign, Atmos. Chem. Phys. Discuss., 8, 6273-6312, 2008,

http://www.atmos-chem-phys-discuss.net/8/6273/2008/.

Claeys, M., Graham, B., Vas, G., Wang, W., Vermeylen, R., Pashynska, V., Cafmeyer, J., Guyon, P., Andreae, M. O., Artaxo, P., and Maenhaut, W.: Formation of Secondary Organic Aerosols through photooxidation of isoprene, Sciences, 103, 1173-1175, 2004.

Cleveland, C. C. and Yavitt J. B.: Consumption of atmospheric isoprene in soil, Geophys. Res. Lett., 24, 2379-2382, 1997.

da Rocha, H. R., Goulden, M. L., Miller, C. D., Menton, M. C., Pinto, L. D. V. O, de Freitas, H. C., and e Silva Figueira, A. M.: Seasonality of water and heat fluxes over a tropical forest in eastern Amazonia, Ecol. Appl., 14(4), S22-S32, 2004.

Dolman, A. J. and Gregory, D.: The parameterization of rainfall interception in GCM's, Q. J. Roy. Meteor. Soc., 118, 455-467, 1992.

Eerdekens, G., Ganzeveld, L., Vilà-Guerau de Arellano, J., Klüpfel, T., Sinha, V., Yassaa, N., Williams, J., Harder, H., Kubistin, D.,
Martinez, M., Fischer, H., and Lelieveld, J.: Flux estimates of isoprene, methanol and acetone from airborne ptrms measurements over the tropical rainforest during the GABRIEL 2005 campaign, submitted to Atmos. Phys. Chem. Discuss., 2008.

Fan, S.-M., Wofsy, S. C., Bakwin, P. S., Jacob, D. J., and Fitzjarrald, D. R.: Atmosphere-biosphere exchange of $\mathrm{CO}_{2}$ and $\mathrm{O}_{3}$ in the Central Amazon forest, J. Geophys. Res., 95, 16 851-16 864, 1990.

Faloona, I., Tan, D., Brune, W., Hurst, J., Barket, D., Couch, T. L., Shepson, P., Apel, E., Riemer, D., Thornberry, T., Carroll, M. A., Sillman, S., Keeler, G. J., Sagady, J., Hooper, D., and Paterson, K.: Nighttime observations of anomalously high levels of hydroxyl radicals above a deciduous forest canopy, J. Geophys. Res., 106(D20), 24 315-24 333, 2001.

Fitzjarrald, D. R. and Moore K. E.: Mechanism of nocturnal exchange between the rain forest and the atmosphere, J. Geophys. Res., 95, 16839-16850, 1990.

Folberth, G. A., Hauglustaine, D. A., Lathière, J., and Brocheton, F.: Interactive chemistry in the Laboratoire de Météorologie Dynamique general circulation model: model description and impact analysis of biogenic hydrocarbons on tropospheric chemistry, Atmos. Chem. Phys., 6, 2273-2319, 2006, http://www.atmos-chem-phys.net/6/2273/2006/.

Ganzeveld, L., Lelieveld, J., Dentener, F. J., Krol, M. C., and Roelofs, G.-J.: Atmosphere-biosphere trace gas exchanges simulated with a single-column model, J. Geophys. Res., 107, 10.1029/2001JD000684, 2002a.

Ganzeveld, L., Lelieveld, J., Dentener, F. J., Krol, M. C., Bouwman, A. F., and Roelofs, G.-J.: The influence of soil-biogenic $\mathrm{NO}_{\mathrm{x}}$ emissions on the global distribution of reactive trace gases: the role of canopy processes, J. Geophys. Res., 107, doi:10.1029/2001JD001289, 2002b.

Ganzeveld, L. and J. Lelieveld: Impact of Amazonian deforestation on atmospheric chemistry, Geophys. Res. Lett., 31, L06105, doi:10.1029/2003GL019205, 2004.

Ganzeveld, L., Klemm, O., Rappenglück, B., and ValverdeCanossa, J.: Evaluation of Micrometeorology over a Coniferous Forest in a Single-Column Chemistry-Climate Model, Atmos. Environ., 40, S21-S27, 2006a.

Ganzeveld, L., Valverde-Canossa, J., Moortgat, G., and Steinbrecher, R.: Evaluation of Peroxide Exchanges over a Coniferous Forest in a Single-Column Chemistry-Climate Model, Atmos. Environ., 40, S68-S80, 2006b.

Guenther, A., Nicolas Hewitt, C., Erickson, D., Fall, R., Geron, C., Graedel, T., Harley, P., Klinger, L., Lerdau, M., McKay, W. A., Pierce, T., Scholes, B., Steinbrecher, R., Tallamraju, R., Taylor, J., and Zimmerman, P.: A global model of natural volatile organic compound emissions, J. Geophys. Res., 100, 8873-8892, 1995.

Guenther, A., Karl, T., Harley, P., Wiedinmyer, C., Palmer, P. I., and Geron, C.: Estimates of global terrestrial isoprene emissions using MEGAN (Model of Emissions of Gases and Aerosols from Nature), Atmos. Chem. Phys., 6, 3181-3210, 2006, http://www.atmos-chem-phys.net/6/3181/2006/.

Harley, P., Greenberg, J., Niinemets, ., and Guenther, A.: Environmental controls over methanol emission from leaves, Biogeosciences, 4, 1083-1099, 2007, http://www.biogeosciences.net/4/1083/2007/.

Houweling, S., Dentener, F., and Lelieveld, J.: The impact of non- 
methane hydrocarbon compounds on tropospheric chemistry, J. Geophys. Res., 103, 10 673-10 696, 1998.

Hüve, K., Christ, M. M., Kleist, E., Uerlings, R., Niinemets, Ü., Walter, A., and Wildt, J.: Simultaneous growth and emission measurements demonstrate an interactive control of methanol release by leaf expansion and stomata, J. Exp. Bot., 58(7), doi:10.1093/jxb/erm0382007, 1783-1793, 2007.

Karl, T., Potosnak, M., Guenther, A., et al.: Exchange processes of volatile organic compounds above a tropical rain forest: Implications for modeling tropospheric chemistry above dense vegetation, J. Geophys. Res., 109, D18306, doi:10.1029/2004JD004738, 2004.

Karl, T., Guenther, A., Yokelson, R. J., Greenberg, J., Potosnak, M., Blake, D. R., and Artaxo, P.: The tropical forest and fire emissions experiment: Emission, chemistry, and transport of biogenic volatile organic compounds in the lower atmosphere over Amazonia, J. Geophys. Res., 112, D18302, doi:10.129/2007JD008539, 2007.

Kesselmeier, J., Kuhn, U., Wolf, A., Andreae, M. O., Ciccioli, P., Brancaleoni, E., Frattoni, M., Ganzeveld, L., Guenther, A., Greenberg, J., De Castro Vasconcellos, P., Tavares, T., and Artaxo, P.: Atmospheric volatile organic compounds (VOC) at a remote tropical forest site in central Amazonia, Atmos. Environ., 34, 4063-4072, 2000.

Kesselmeier, J., Kuhn, U., Rottenberger, S., et al.: Concentrations and species composition of atmospheric volatile organic compounds (VOCs) as observed during the wet and dry season in Rondonia (Amazonia), J. Geophys. Res., 107(D20), 8053, doi:10.1029/2000JD000267, 2002.

Kroll, J. H., Ng, N. L., Murphy, S. M., Flagan, R. C., and Seinfeld, J. H.: Secondary organic aerosol formation from isoprene photooxidation, Environ. Sci. Technol., 40, 1869-1877, 2006.

Kuhn, U., Andreae, M. O., Ammann, C., Araújo, A. C., Brancaleoni, E., Ciccioli, P., Dindorf, T., Frattoni, M., Gatti, L. V., Ganzeveld, L., Kruijt, B., Lelieveld, J., Lloyd, J., Meixner, F. X., Nobre, A. D., Pöschl, U., Spirig, C., Stefani, P., Thielmann, A., Valentini, R., and Kesselmeier, J.: Isoprene and monoterpene fluxes from Central Amazonian rainforest inferred from towerbased and airborne measurements, and implications on the atmospheric chemistry and the local carbon budget, Atmos. Chem. Phys., 7, 2855-2879, 2007, http://www.atmos-chem-phys.net/7/2855/2007/.

Landgraf J. and Crutzen, P. J.: An efficient method for online calculations of photolysis and heating rates, J. Atmos. Chem., 55, 863-878, 1998.

Lathière, J., Hauglustaine, D. A., Friend, A. D., De NobletDucoudré, N., Viovy, N., and Folberth, G. A.: Impact of climate variability and land use changes on global biogenic volatile organic compound emissions, Atmos. Chem. Phys., 6, 2129-2146, 2006,

http://www.atmos-chem-phys.net/6/2129/2006/.

Lelieveld, J., Butler, T. M., Crowley, J., Dillon, T., Fischer, H., Ganzeveld, L., Harder, H., Kubistin, D., Lawrence, M. G., Martinez, M., Taraborrelli, D., and Williams, J.: Atmospheric oxidation capacity sustained by a tropical forest, Nature, 452, 7188, doi:10.1038/nature06870, 737-740, 2008.

Martinez, M., Harder, H., Kubistin, D., Rudolf, M., Bozem, H., Eerdekens, G., Fischer, H., Gurk, C., Klüpfel, T., Königstedt, R., Parchatka, U., Schiller, C. L., Stickler, A., Williams, J., and
Lelieveld, J.: Hydroxyl radicals in the tropical troposphere over the Suriname rainforest: airborne measurements, Atmos. Chem. Phys. Discuss., 8, 15 491-15 536, 2008, http://www.atmos-chem-phys-discuss.net/8/15491/2008/.

Meixner, F. X. and Yang, W. X.: Biogenic emissions of nitric oxide and nitrous oxide from arid and semi-arid land, in: Dryland Ecohydrology, edited by: D'Odorico, P. and Porporato, A., Springer, Dordrecht, The Netherlands, 233-255, 2006.

Moldrup, P., Olesen, T. R., Gamst, J., Schjonning, P., Yamaguchi, T., and Rolston, D. E.: Predicting the gas diffusion coefficient in repacked soil: Water-induced linear reduction model, Soil Sci. Soc. Am. J., 64, 1588-1584, 2000.

Niinemets, $\ddot{U}$ and Reichstein, M.: Controls on the emission of plant volatiles through stomata: A sensitivity analysis, J. Geophys. Res., 108, 4211, doi:10.1029/2002JD002626, 2003.

Olson, J.: World ecosystems (WE1.4): Digital raster data on a 10 minute geographic $1080 \times 2160$ grid square, in: Global Ecosystem Database, Version 1.0: DISC A, edited by: NOAA National Geophysical Data Center, Boulder, CO, USA, 2002.

Parton, W. J., Holland, E. A., Del Grosso, S. J., Hartman, M. D., Martin, R. E., Mosier, A. R., Ojima, D. S., and Schimel, D. S.: Generalized model for $\mathrm{NO}_{\mathrm{x}}$ and $\mathrm{N}_{2} \mathrm{O}$ emissions from soils, J. Geophys. Res., 106, 17 403-17 419, 2001.

Roeckner, E., Bäuml, G., Bonaventura, L., Brokopf, R., Esch, M., Giorgetta, M., Hagemann, S., Kirchner, L., Kornblueh, L., Manzini, E., Rhodin, A., Schlese, U., Schulzweida, U., Tompkins, A.: The atmospheric general circulation model ECHAM5. Part I: Model description, Report 349, Max Planck Institute for Meteorology, Hamburg, Germany, available at: http://www. mpimet.mpg.de, 2003.

Roelofs, G.-J. and Lelieveld, J.: Tropospheric ozone simulation with a chemistry-general circulation model: Influence of higher hydrocarbon chemistry, J. Geophys. Res., 105, 22 697-22 712, 2000.

Rummel, U., Ammann C., Kirkman, G. A., Moura, M. A. L., Foken, T., Andreae, M. O., and Meixner, F. X.: Seasonal variation of ozone deposition to a tropical rain forest in southwest Amazonia, Atmos. Chem. Phys., 7, 5415-5435, 2007, http://www.atmos-chem-phys.net/7/5415/2007/.

Sellers, P. J., Mintz, Y., Sud, Y. C., and Dalcher, A.: A simple biosphere model (SiB) for use within general circulation models, J. Atmos. Sci., 43, 505-531, 1986.

Sellers, P. J., Shuttleworth, W. J.., Dorman, J. L., Dalcher, A., and Roberts, J. M.: Calibrating the Simple Biosphere model for Amazonian tropical forest using field and remote sensing data. Part I: Average calibration with field data, J. Appl. Meteorol., 28, 727-759, 1989.

Stickler, A., Fischer, H., Bozem, H., Gurk, C., Schiller, C., Martinez-Harder, M., Kubistin, D., Harder, H., Williams, J., Eerdekens, G., Yassaa, N., Ganzeveld, L., Sander, R., and Lelieveld, J.: Chemistry, transport and dry deposition of trace gases in the boundary layer over the tropical Atlantic Ocean and the Guyanas during the GABRIEL field campaign, Atmos. Chem. Phys., 7, 4781-4855, 2007,

http://www.atmos-chem-phys.net/7/4781/2007/.

van Dijk, S. M., Gut, A., Kirkman, G. A., Meixner, F. X., and Andreae, M. O.: Biogenic NO emissions from forest and pasture soils: Relating laboratory studies to field measurements, J. Geophys. Res., 107, LBA 25-1-LBA 25-11, 2002. 
Vilà-Guerau de Arellano, J. and van den Dries, K.: Ozone vertical and diurnal variability influenced by shallow cumulus: LargeEddy Simulation study, 15th International Conference on Clouds and Precipitation ICCP, Cancun, Mexico, 2008.

von Kuhlmann, R., Lawrence, M. G., and Crutzen, P. J.: A model for studies of tropospheric ozone and nonmethane hydrocarbons: Model descriptions and ozone results, J. Geophys. Res., 108, doi:10.1029/2002JD002893, 2003.

Walmsey, J. L. and Wesely, M. L.: Modification of coded parameterizations of surface resistances to gaseous dry deposition, Atmos. Environ. 30, 1181-1188, 1996.

Warneke, C., Holzinger, R., Hansel, A., Jordan, A., Lindinger, W., Pöschl, U., Williams, J., Hoor, P., Fischer, H., Crutzen, P. J., Scheeren, H. A., and Lelieveld, J.: Isoprene and its oxidation products methyl vinyl ketone, methacrolein, and isoprene related peroxides measured online over the tropical rain forest of Surinam in March 1998, J. Atmos. Chem., 38(2), 167-185, 2001.
Wesely, M. L.: Parameterization of surface resistances to gaseous dry deposition in regional-scale numerical models, Atmos. Environ., 23, 1293-1304, 1989.

Williams, J., Yassaa, N., Bartenbach, S., and Lelieveld, J.: Mirror image hydrocarbons from Tropical and Boreal forests, Atmos. Chem. Phys., 7, 973-980, 2007, http://www.atmos-chem-phys.net/7/973/2007/.

Yienger, J. J. and Levy, H.: II. Global inventory of soil-biogenic $\mathrm{NO}_{\mathrm{x}}$ emissions, J. Geophys. Res., 100, 11 447-11 464, 1995. 